\title{
Tech Start-up Ecosystem in Beirut
}

\section{FINDINGS AND RECOMMENDATIONS}

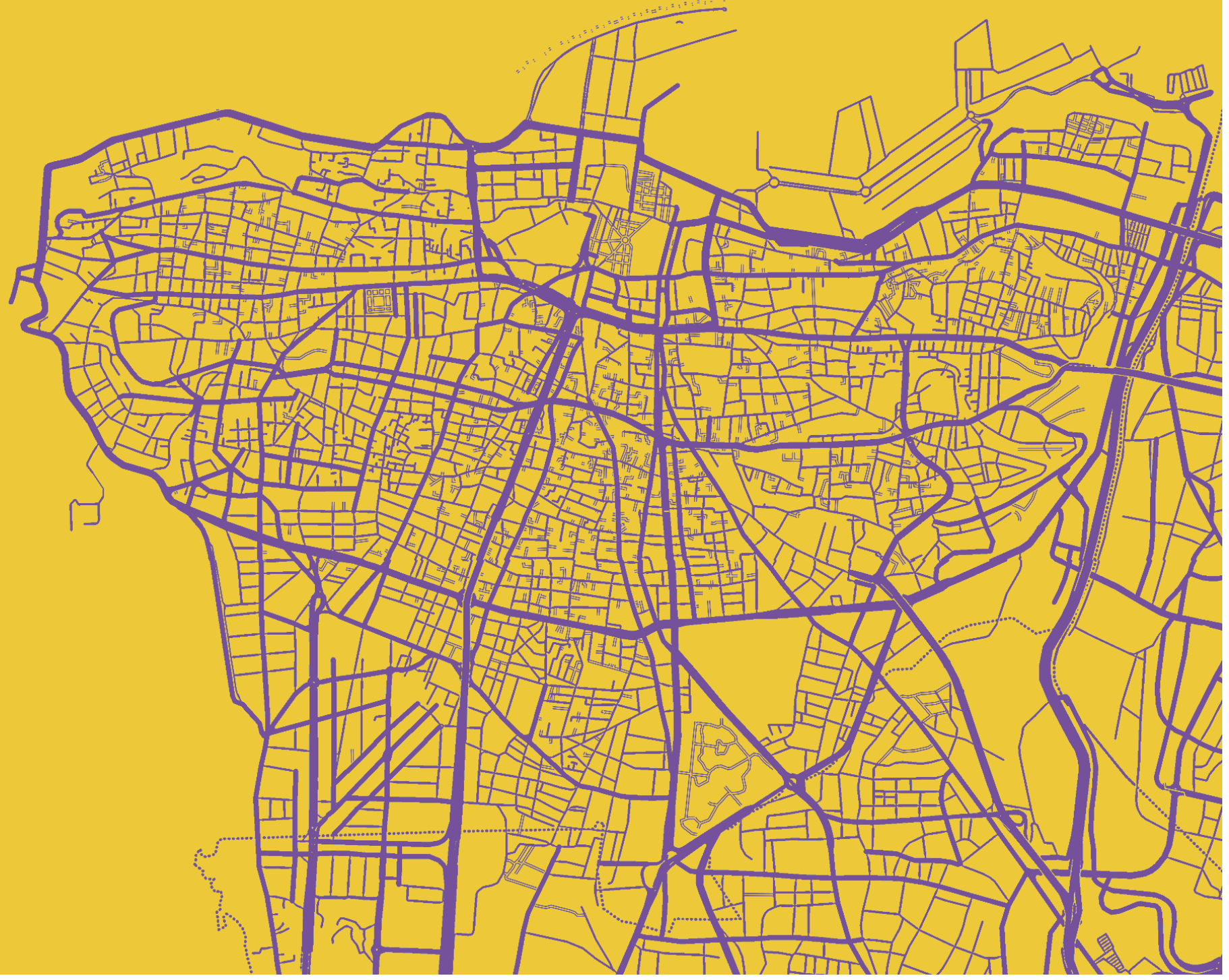


Authors and Acknowledgements

Executive Summary $\quad 2$

Measuring and Analyzing the Tech Start-up Ecosystem in Beirut 5

Measuring the Tech Start-up Ecosystem $\quad 5$

$\begin{array}{ll}\text { Analyzing the Tech Start-up Ecosystem } & 6\end{array}$

The Tech Start-up Ecosystem in Beirut 9

$\begin{array}{ll}\text { Skills } & 11\end{array}$

$\begin{array}{ll}\text { Supporting Infrastructure for Entrepreneurship } & 13\end{array}$

$\begin{array}{ll}\text { Investment } & 15\end{array}$

$\begin{array}{ll}\text { Community } & 16\end{array}$

$\begin{array}{ll}\text { Start-up Success Factors } & 19\end{array}$

Gap Analysis and Policy Recommendations $\quad 20$

Summary of Gap Analysis and Stage of Ecosystem $\quad 20$

Policy Recommendations $\quad 21$

$\begin{array}{ll}\text { Program in Focus: Circular } 331 & 24\end{array}$

$\begin{array}{ll}\text { References } & 26\end{array}$

$\begin{array}{ll}\text { Survey Methodology and Analysis } & 27\end{array}$ 


\section{LIST OF TABLES}

$\begin{array}{ll}\text { Table 1.1 Networking Assets (Ecosystem's Support Infrastructure) } & 7\end{array}$

Table 1.2 Categories of Ecosystems 8

Table 3.1 Development Stage of Ecosystem (Per Area and Overall) 20

Table 3.2 Policy Recommendations 21

\section{LIST OF FIGURES}

Figure 2.1 Start-up Growth in Beirut, 2009-2015 9

Figure 2.2 Time to Complete Procedural Tasks in Life Cycle of a Start-up Across Regions $\quad 10$

Figure 2.3 Gender Distribution and Job Functions of Founders $\quad 10$

$\begin{array}{ll}\text { Figure 2.4 Average Age of Founders } & 11\end{array}$

$\begin{array}{ll}\text { Figure 2.5 Educational Level of Founders in Beirut } & 11\end{array}$

Figure 2.6 Highest Degree Earned by Founders at Time of Founding 12

Figure 2.7 Educational Experience of Founders in Beirut $\quad 13$

Figure 2.8 Previous Function and Role Type of Founders in Beirut 12

Figure 2.9 Accelerator Programs Attended by Start-ups in Beirut $\quad 14$

Figure 2.10 Accelerator's Quality/Quantity Ratio (Selected cities) $\quad 14$

Figure 2.11 Median Investment Amount by Year of Existence $\quad 15$

Figure 2.12 Growth of Founders and Connections in Beirut 16

$\begin{array}{ll}\text { Figure 2.13 Connections in Beirut's Tech Ecosystem } & 17\end{array}$

$\begin{array}{ll}\text { Figure 2.14 Progression of Ecosystem Connectivity } & 18\end{array}$

$\begin{array}{ll}\text { Figure 2.15 Short-Term Success } & 19\end{array}$

Figure 2.16 Circular 331 Effectiveness in Various Areas $\quad 24$

Figure2.17 Effect of Circular 331 on Raising Funding and Developing the Support System $\quad 25$

\section{List of Boxes}

Box 1.1 GERN Ecosystems Connection Project $\quad 6$

$\begin{array}{ll}\text { Box 2.1 Accelerators and Incubators } & 13\end{array}$

Box 3.1 What is Circular 331? 22

Box 3.2 What Are Coding Bootcamps? 23 


\section{Terms Used}

Start-up

Start-up Ecosystem

Scale-up (Firm)

Venture Capital (VC)

Angel Investor

Mentor

Business Acumen

Exit

(start-up exit)
A newly established business venture that is in its first stages of operation. This report focuses on tech start-ups, which are start-ups that have a technological component. These start-ups are typically designed to scale up quickly.

The combination of people, start-ups at various stages and other stakeholders and organizations supporting or connecting to these start-ups, interacting in multiple dimensions to create and scale new start-up ventures.

OECD defines a scale-up as a firm that has an average annualized return of at least 20 percent in the past three years with at least 10 employees at the beginning of the period (OECD 2007).

An institutional investor that provides financing to start-ups and small early stage firms. Usually VCs look for high growth potential firms to exit the investment in the short term.

An investor who invest in ventures (primarily at an early stage) in their personal capacity (that is, investing their personal money) and may or may not have an active advisory or guidance role for the founders in the venture.

An experienced person who can provide advice, knowledge, or connections to a start-up founder. Mentors usually have strong business acumen and practical experience through former entrepreneurship experience or industry knowledge.

Theoretical or practical knowledge of how to develop and manage a business, including proclivity and speed in understanding and dealing with risks and opportunities in the business environment.

Refers to the point at which a founder or early stage investors sell their stakes in the venture, generally either in a private acquisition or public offering. This report refers more widely to "start-up exit" as the point at which a start-up is sustainable or it has received sufficient funding to grow in the medium-term (that is, over the next five years). 


\section{Authors and Acknowledgements}

The authors of this report are Victor Mulas, Kathy Qian, and Scott Henry. Matt Lerner, Kwame Robinson, Mireille Raad, Anastasia Nedayvoda, Ainsley Lloyd, Nga Nguyen, Cecilia Paradi-Guilford, and Elene Allende Letona contributed to this report through data, economic analysis and inputs. The survey was conducted by Endeavor Lebanon, and Berytech complemented the data collection. The Ministry of Economy of Lebanon also provided support through data access and outreach. The report was edited by Colin Blackman (Camford Associates) and designed by Wenceslao Almazan. The peer reviewers were Randa Akeel, Wissam Harake, Abdalwahab Khatib, and Zeina El Khoury. This report was partially funded by the World Bank and the Korean Partnership Facility. We are grateful to Endeavor Lebanon, and particularly its Managing Director, Tarek Sadi, for the valuable in-kind contribution to the survey collection process, guidance and advice through this process. 


\section{Executive Summary}

Technology is one of the main drivers of productivity and economic growth (Isaksson, $\mathrm{Ng}$, and Robyn 2005). Developing countries have traditionally had difficulties in both developing technology and absorbing foreign technology. Seventy to eighty percent of the productivity gap between developed and developing countries is estimated to result from the lag in the adoption of technologies in these countries (Comin and Marti 2013; and Comin and Hobijn 2010).

Tech start-ups are an effective mechanism to both create local technology and absorb foreign technology. In recent years, there has been a surge in tech start-ups across the world. Fueled by global technology-led cost reductions and increased access to resources, tech entrepreneurs have emerged in both developed and developing countries. However, there is very little understanding of how these tech entrepreneurs form ecosystems, their internal dynamics of these ecosystems, how they work, what makes them grow and achieve sustainability, how they connect with the local economy to drive productivity and employment, and why some ecosystems are more effective than others.

This report is part of a broader research initiative (See Box 1.1) aiming to provide answers to these questions. It provides new data and analysis of the tech start-up ecosystem in Beirut. The analysis comprises: (i) an attempt to provide an accurate description and measurement of the city's tech start-up ecosystem; and (ii) a comparison and gap analysis of four key components of the tech start-up ecosystem (skills, finance, entrepreneurial supporting infrastructure, and community).

The objective of this report is to provide a better understanding of the status of Beirut's start-up ecosystem and provide policy recommendations for policymakers and other stakeholders who are interested in supporting the growth and sustainability of the ecosystem.

\section{Analysis Limitations}

Measuring the tech start-up ecosystem is difficult. Relevant databases of start-ups are not readily available, and the fast-paced and multidimensional dynamics of start-up ecosystems, with new ventures constantly being created, failing, being closed, being bought or transformed (changing names and/or purpose), makes accurate measurement over time inherently difficult.

For this analysis, 218 entrepreneurs were surveyed in Lebanon between February and August 2016 and relevant data was collected for 142 start-ups and 196 start-up founders. ${ }^{1}$ The survey was based on the standard questionnaire from the Global Entrepreneurship Research Network (GERN) Ecosystem Connection project (see Box 1.1). The findings and conclusions of this analysis are based on this survey 
and so there are some limitations to this analysis. The dataset is not exhaustive and only represents a subset of the ecosystem's start-ups. Moreover, it is subject to survivorship bias and does not include start-ups that were no longer in business when data was collected. Historical data about start-ups was collected through existing founders who were available at the time of the survey.

Despite these limitations, the subset of startups surveyed provides unique insights into the ecosystem. Data was collected by snowballing from public data contained in existing databases, networks from key stakeholders (for example, accelerators, events, and so on), as well as recommendations from founders. Although there are start-ups that were not captured in this survey, nevertheless it provides one of the richest samples of data collected to date on the most influential founders, start-ups, intermediaries, and other ecosystem stakeholders in Beirut.

\section{Findings}

The tech start-up ecosystem in Beirut is an early-tomiddle stage ecosystem that has passed its nascent growth phase but is still far from maturity (see table below). The key strengths of the ecosystem are the presence of talented people, with highly educated founders ( 90 percent of them having a university degree and 50 percent with graduate degrees) with sufficient relevant experience, and the availability of funding for early-stage start-ups (a unique characteristic for this stage of development of an ecosystem).

The supporting infrastructure (for example, accelerators, mentors) and the community is still maturing. Accelerator programs do not seem to provide sufficient quality training for entrepreneurs to be sustainable and quality mentors are scarce, with few instances of angel investors. Events and community building appear to have been catalyzed by the programs of the Banque Du Liban (BDL), the Central Bank of Lebanon (BDL Accelerate and Circular 331), and donor and government action still drive many activities in the ecosystem. Since the entrepreneurial community is still in its early stages, like-minded individuals do not connect easily with one another to form clusters, suggesting a silo approach among ventures from different networks.

Investment is currently abundant but there are signs that a start-up bubble may be forming, distorting the ability of the ecosystem to select the best start-ups and generate success stories that are sustainable over time. Compared to other early and middle stage ecosystems (such as in Tanzania and West Bank \& Gaza), processes in Beirut for start-ups are lengthier for credit and funding (with West Bank \& Gaza), suggesting more difficulties (linked to procedures or access to finance requirements) in obtaining funding for start-ups. Finally, sustainability of the current level of access to funding, which is fueling the ecosystem, is not ensured without current policy intervention (Circular 331), which may be crowding out sources of more sustainable private investment. 


\section{DEVELOPMENT STAGE OF BEIRUT'S START-UP ECOSYSTEM}

\begin{tabular}{|c|c|c|c|c|}
\hline \multirow{2}{*}{\multicolumn{2}{|c|}{ Ecosystem Area }} & \multicolumn{3}{|l|}{ Stage } \\
\hline & & Nascent & Advancing & Mature \\
\hline & 1. Community & \multicolumn{3}{|c|}{0} \\
\hline & 2. Skills & \multicolumn{3}{|c|}{0} \\
\hline ז'ロ & 3. Supporting Infrastructure & \multicolumn{3}{|c|}{0} \\
\hline 8 & 4. Investment & \multicolumn{3}{|c|}{0} \\
\hline & 5. Constraints & \multicolumn{2}{|c|}{0} & \\
\hline & OVERALL & \multicolumn{3}{|c|}{0} \\
\hline
\end{tabular}

\section{Policy Recommendations}

Based on this analysis, a set of policy recommendations were developed (see table below), which are further expanded in the report.

\section{Ecosystem Area}

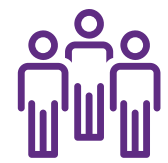

Community

\section{Policy Recommendation}

Strengthen coordination mechanism and ecosystem support program with stakeholders

\section{Objective}

Expand cluster connectivity, coordinate private and public action and increase density of connections among all stakeholders

Expand ecosystem community to traditional industries and absorb international connectivity international talent connectivity, connect with domestic corporate nontech sectors

Expand practical education in university and through rapid skills training programs and include public education programs
Address practical business acumen gaps, provide pipeline of talent for start-up scale-up, and include lower income/educated population

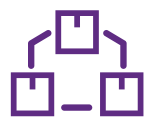

Support Infrastructure
Increase capacity building of mentors in accelerators and attraction of international talent (as mentors, entrepreneurs or capacity builders) to the ecosystem
Address lack of sufficient number of quality mentors and strengthen support services

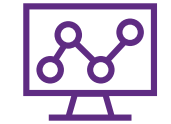
Investment
Assess quality of start-up funding and prepare phase out of Circular 331 introducing private sector funding
Address potential bubble of start-ups and distortion of investment market, and ensure sustainability of funding
Address processes constraints (for example, access to loans and funding)
Reduce constraints for start-ups incorporation and operationalization 


\section{Measuring and Analyzing the Tech Start-up Ecosystem in Beirut}

This report provides an analysis of the tech start-up ecosystem in Beirut. The analysis comprises: (i) an attempt to provide an accurate description and measurement of the city's tech startup ecosystem and (ii) a comparison and gap analysis of four key components of the tech start-up ecosystem (skills, finance, entrepreneurial supporting infrastructure, and community).

For the purposes of this report, tech start-ups are defined as for-profit business ventures that a) have a financial model targeting high growth, and b) employ an innovative and technology-enabled approach to the product or service that they provide to ensure scalability. These ventures may not be profitable at their current stage.

In order to capture the whole tech start-up ecosystem, this report expands the concept of start-ups to include newly emerging start-ups as well as small and medium enterprises (SMEs) that were once start-ups and have reached the scaling phase. This definition allows us to collect data to describe the evolution of the tech start-up ecosystem over time as start-ups grow and succeed. Since the aim of this report is to analyze the start-up ecosystem, all relevant ventures and actors that have an influence on the ecosystem are included, even though they may no longer be start-ups.

\section{Measuring the Tech Start-up Ecosystem}

Measuring the tech start-up ecosystem is a difficult task. Relevant databases of start-ups are not readily available, and the fast-paced and multidimensional dynamics of start-up ecosystems, with new ventures constantly being created, failing and being closed, and being bought or transformed (changing names and/or purpose), makes accurate measurement over time inherently difficult.

Some databases have tried to collect information on startups. These databases are global, local (mostly at the level of metropolitan areas' ecosystems) and, in some cases, domestic (countrywide). Databases are both open and proprietary. Access to proprietary databases is limited and in some cases restricted (not being open to wider research). The most relevant open databases of start-ups are provided by CrunchBase and AngelList. Neither of these databases, however, necessarily provide accurate or complete information. CrunchBase is a selfreported database that is not curated by an official entity, and as such it can have inaccurate information such as closed or transformed ventures still being posted with the original data, founders omitted, and so on. AngelList generally contains more accurate information since start-ups listed there have received or are actively soliciting investment from angel investors or venture capital (VC) firms. Other global start-up repositories, such as Startup Genome, ${ }^{2}$ build on these databases with additional self-reporting data from start-ups, and therefore are subject to similar limitations. Finally, while Linkedln can provide more accurate data of start-ups through funders and employers, data access and use restrictions make its use for independent research purposes difficult.

These global databases, however, are of little use in building an overall picture of the tech start-up ecosystem in many developing countries, as they contain little information on these regions. At the time of conducting this analysis, CrunchBase contained only 122 start-ups from Lebanon, and AngelList only 126.

Regional and local start-up databases can be richer in data and more accurate, since they are often the result of an active effort to track the activity and lifecycle of start-ups. Examples of these databases are Digital $\mathrm{NYC}^{3}$ in New York or Tech Map ${ }^{4}$ in London. However, these databases are not present in many ecosystems, particularly in developing country ecosystems, and given their localized methodologies, their data is difficult to utilize for comparative analytics. Other datasets, such as that of the Global Accelerator Learning Initiative, ${ }^{5}$ only have enough power to report data at the regional level.

While official government or NGO-managed databases in developing countries can provide richer and more accurate 
data from SMEs and larger companies, they also lack both data breadth and depth when it comes to start-ups. In the case of Lebanon, the last official census was conducted in 1931.

To combat the poor availability of data, a survey was designed and deployed by extending the standard questionnaire from the Global Entrepreneurship Research Network (GERN) Ecosystem Connection project (see Box 1.1). For a broader description and technical details of this survey, see Appendix A. We surveyed 218 entrepreneurs in Lebanon from February to August 2016 using an online interactive questionnaire distributed through local partners by email, phone, and in person. ${ }^{6}$ From these interviews, data for 142 relevant start-ups and 196 start-up founders were collected. This sample provides unique insights into the characteristics of founders, start-ups, investors, and supporting infrastructure in Beirut, as well as the relationships between them. ${ }^{7}$

The resulting dataset is not exhaustive, however, and only represents a subset of the Beirut ecosystem's start-ups. Moreover, it is subject to survivorship bias and does not include start-ups that were no longer in business when data

\section{BOX 1.1 GERN ECOSYSTEMS CONNECTION PROJECT}

The Ecosystem Connections Mapping Project aims to map start-up ecosystems across the world by collecting data on start-up founders (for example, education, work experience, serial entrepreneurship, and so on) and the connections between themselves and other key stakeholders in their ecosystem (for example, mentors, investors, accelerators, universities, and so on) to better understand and support entrepreneurs in local start-up ecosystems. This data aims to identify gaps in ecosystems and provide a base for policy action to address these gaps and support growth and sustainability of start-up ecosystems.

The project has mapped over ten start-up ecosystems in cities across the world (including, Bogota, Cairo, London, New York, and Singapore). The survey conducted for this report is also part of this project, adding Beirut to the ecosystems mapped. The leading partners of this project are Endeavor Insight and the World Bank.

Source: http://gern.co/gern/ecosystem-connectionsmapping. was collected. Historical data about start-ups was collected from existing founders available at the time of the survey. These limitations are discussed in detail in the Methodology section of Appendix A. Despite these limitations, the subset of start-ups surveyed is likely to be representative sample since the start-up data was collected by snowballing from public data contained in existing databases, networks from key stakeholders (for example, accelerators, events, and so on), and recommendations from founders. Although there are start-ups that were not captured in this survey, nevertheless it provides one of the richest samples of data collected to date on the most influential founders, start-ups, intermediaries, and other ecosystem stakeholders in Beirut.

This report assumes that, owing to the fast-moving nature of start-up ecosystems, any attempt to accurately measure the tech start-up ecosystem is inherently flawed - any measurement will be obsolete immediately after collection. The findings and recommendations provided in this analysis should be taken with this limitation in mind. Less emphasis should be placed on exact numbers, which are subject to change with the addition of more start-ups and sensitive to minor tweaks in methodology. Rather, the data collected provides insights into general trends and the dynamics of the ecosystem that can inform specific policies. This analysis should not be considered in isolation, however, and policy makers are encouraged to confirm these findings through other available resources (for example, perspectives from practitioners and anecdotal evidence).

\section{Analyzing the Tech Start-up Ecosystem}

The following analysis of the tech start-up ecosystem in Beirut is based on the data collected through the survey described above. This report analyzes four key elements: i) skills, ii) finance, iii) supporting infrastructure for entrepreneurship, and iv) community. The analysis first describes the status of each of these elements based on the data collected, and then compares the results with those reported by both average and successful start-up founders.

Constraints for start-up founders and the ecosystem are described in as much as they are referred by founders. We acknowledge this report does not cover all existing constraints, such as broadband or physical infrastructure in the city, which may well help expand the ecosystem. ${ }^{8}$

For the purposes of this analysis, successful start-ups are defined as those that have been funded and those who employ people. "Short-term success" is defined as obtaining funding from at least one investor; "long-term success" is defined as continuously hiring employees (as a proxy for growth).

Comparing average founders and start-ups with successful ones highlights which characteristics (in terms of education, 
experience, connections, and so on) are more predominant in successful start-ups in Beirut and whether they are consistent with those in other ecosystems or with global trends (where data is available). Where comparable data is available on other ecosystems surveyed under the GERN Ecosystems Connections Project, local results are benchmarked with other ecosystems to understand if there are gaps that could be addressed.

The four elements this report analyzes represent the key ingredients needed for tech start-up ecosystems to grow and be sustainable. Skills aims at understanding the educational and work experience that founders have and those that are more common for successful founders. Finance looks at the funding obtained by start-ups during their lifecycle and the general availability of such funds. Supporting infrastructure for entrepreneurship seeks to understand the quantity and quality of support programs and resources for start-ups to succeed. Supporting infrastructure encompasses accelerators and incubators, mentors, events, and other ecosystem and/ or skills-building resources. Finally, community looks at the maturity of the ecosystem as a network of stakeholders that support each other (directly or indirectly) for the successful outcome of start-ups.

This report uses comparable data from other ecosystems to produce benchmarking analysis when homogenous data is available. Given limitations of start-up data across start-up ecosystems, the analysis of this report will use available data as proxies for comparable start-up ecosystems at different level of maturity (regardless of region). For instance, Dar es Salaam's (Tanzania) ecosystem is used as a nascent ecosystem and West Bank \& Gaza's ecosystem as an advancing one. We understand these proxies may not be a perfect comparison but we believe they can still provide a valuable reference point.

This analysis is conducted under the premise that startup ecosystems are communities of stakeholders and that the success of such ecosystems is linked to the maturity, health, and sustainability of the community. Previous research of the World Bank (Mulas, Minges, and Applebaum 2015) shows that tech start-up ecosystems act as communities and that centrality (that is, the number of ecosystem' stakeholders a founder of start-up is connected to directly or indirectly) is critical for start-up success. This finding is also consistent with research from Endeavor Insight showing that access to mentors increases the probability of start-up success. ${ }^{9}$ In this environment, the supporting infrastructure acts both as a skills and network provider and is critical for ecosystem sustainability. The ecosystem's supportive infrastructure is mainly comprised of networking assets (see Table 1.1).

\section{TABLE 1.1 NETWORKING ASSETS (ECOSYSTEM'S SUPPORT INFRASTRUCTURE)}

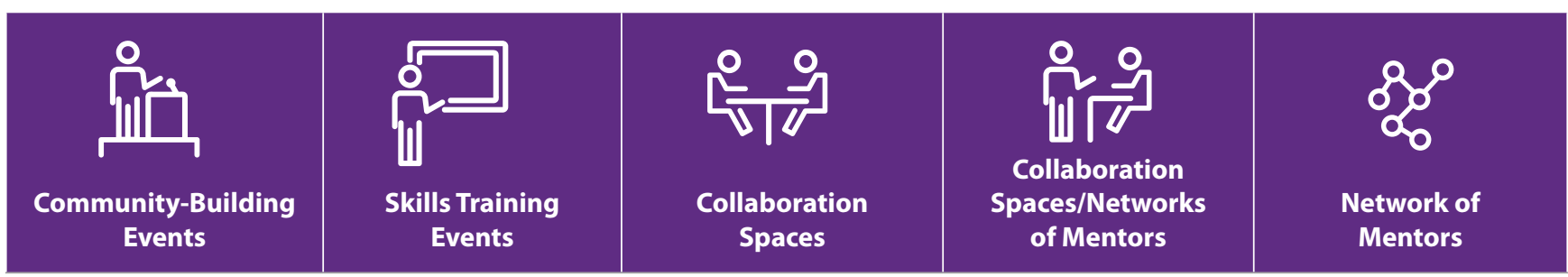

$\begin{array}{ll} & \text { Bootcamps and } \\ \text { Meetups } & \text { technology training } \\ & \text { linked to community } \\ \text { building }\end{array}$

Bootcamps and linked to community building
Collaboration and community-building spaces (e.g., coworking spaces, makerspaces, fab labs)
Accelerators (network value)

Angel investors (network value)

$\begin{array}{ll}\text { Tech community } & \text { Rapid technical and } \\ \text { events/conferences } & \text { entrepreneurial skills } \\ & \text { programs }\end{array}$

Incubators (network value)

\section{Venture capital} (network value)

Networks of mentors and start-up "alumni" networks (if different from accelerators, incubators, angel investors, and venture capital) 
Based on these four elements, the analysis categorizes ecosystems into three broad categories: a) nascent ecosystems, b) advancing ecosystems, and c) mature ecosystems (see Table 1.2).

a) Nascent Ecosystem. There are a limited number of startups, most of which are in the very early or early stages. The community of entrepreneurs is forming, and has low density of connections with few clusters, if any. In these ecosystems founders lack business experience, mentors are scarce and inexperienced and there are very few generations of entrepreneurs (most entrepreneurs are in their first or second venture), there are few or no start-up exits or if there are any, they are outliers. There are few or no international connections. The finance pipeline has multiple gaps and private early stage finance is very rare (if it exists).

b) Advancing Ecosystem. These ecosystems have an increased number of start-ups, with most in the early stages but with increasing numbers of scale-ups. The community of entrepreneurs has several clusters and a high density, and there are a handful of successful start-up exits. There is still a lack of business acumen among entrepreneurs but there are a growing number of serial entrepreneurs and the ecosystem has more than three generations of start-ups. There are an increasing number of international connections and mentors with local start-up experience. The finance pipeline is starting to form with increasing private sector investment in early stage star-ups, but there are still gaps in the path to scale up and exit.

c) Mature Ecosystem. These ecosystems have a large number of start-ups in all stages (for example, growing, scaling up, exits) and the ecosystem is highly interconnected. The majority of entrepreneurs have business acumen and previous relevant business experience, there are several generations of start-ups with multiple serial entrepreneurs and successful exits. Mentors are abundant, they have solid practical experience, and there is a solid base of angel investors. The ecosystem is an international hub itself and attracts international talent. The finance pipeline has no gaps and early stage funding is provided by sustainable private funds.

These categories are broad and serve to provide a sense of where ecosystems are in their life cycle. As this research continues and we can access data from a larger sample of ecosystems from the GERN Ecosystems Connection project, we will be able to provide more concrete metrics on these stages.

This report focuses on supply-side factors of start-up ecosystems and does not analyze extensively the demand side. Further analysis would need to be conducted to understand deeply demand-side factors.

\section{TABLE 1.2 CATEGORIES OF ECOSYSTEMS}

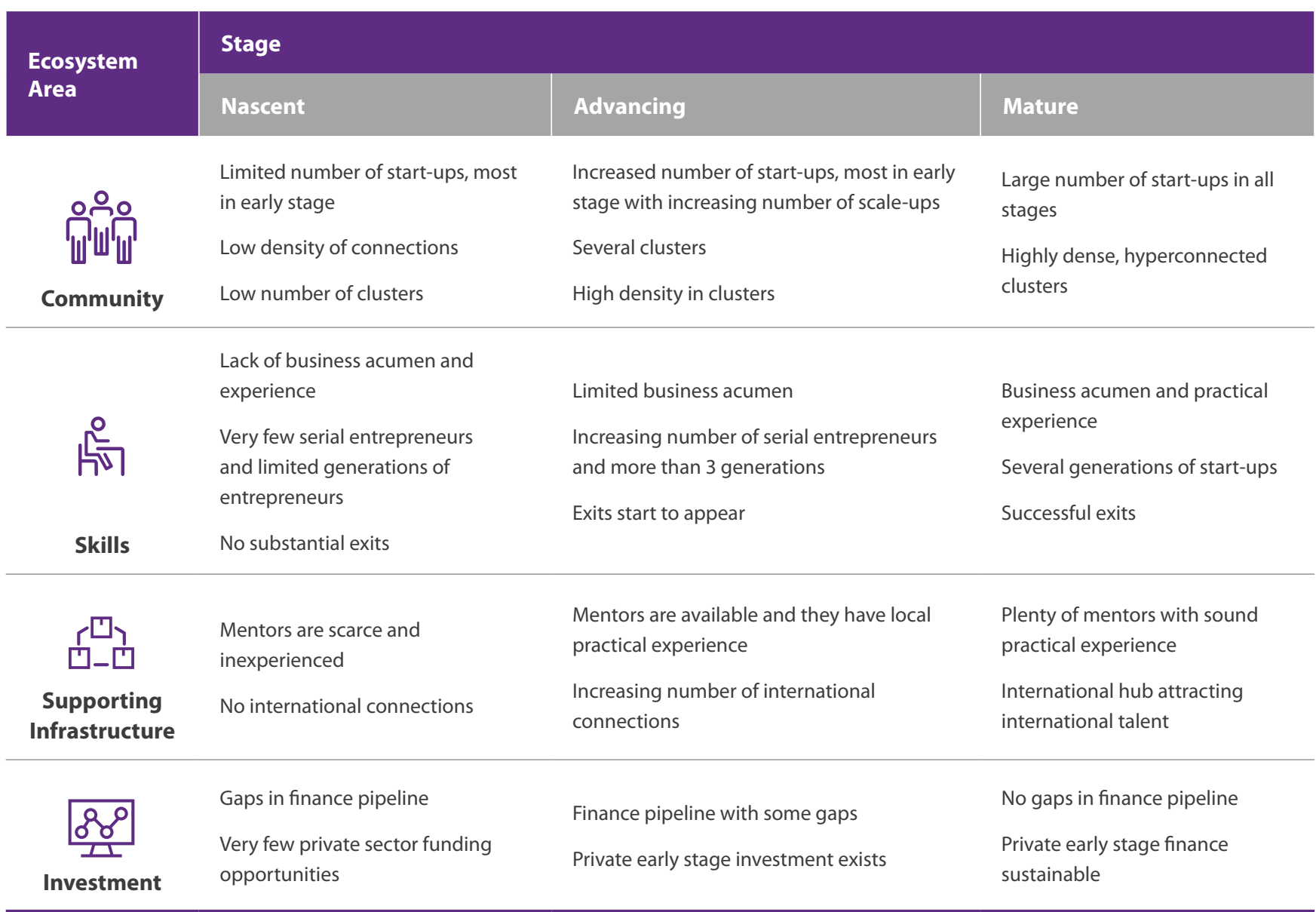




\section{The Tech Start-up Ecosystem in Beirut}

The tech start-up ecosystem in Beirut is an early to middle stage ecosystem, that has passed its nascent growth phase but is still far from maturity. On average, each year, 12 more start-ups are created than in the previous year, resulting in a 24 percent compound growth rate in start-up creation since 2009 (see Figure 2.1$)^{10}$

About two-thirds of the start-ups surveyed reported hiring at least one employee, with a median of three jobs per start-up, consistent with the evolving stage of an ecosystem, with startups primarily in their early stage.

Start-ups in Beirut face some bureaucratic hurdles in their life cycle (see Figure 2.2). Ventures can rapidly open a bank account but incorporation, renting an office, hiring qualified personnel, and obtaining a credit line from a bank typically takes about a month. Obtaining funding is a much lengthier process taking about four months to close (for example, individual or institutional investor).

Compared to other early and middle stage ecosystems (such as Dar es Salaam, Tanzania, and West Bank \& Gaza), processes in Beirut are lengthier for receiving credit and funding (with West Bank \& Gaza), indicating greater difficulty (linked to procedures or access to finance requirements) in obtaining funding for start-ups. The contrast with West Bank \& Gaza's ecosystem is particularly striking: in Beirut, it takes twice as long for a start-up to obtain credit and almost four times as long to receive funding. ${ }^{11}$

\section{FIGURE 2.1 START-UP GROWTH IN BEIRUT, 2009-2015}

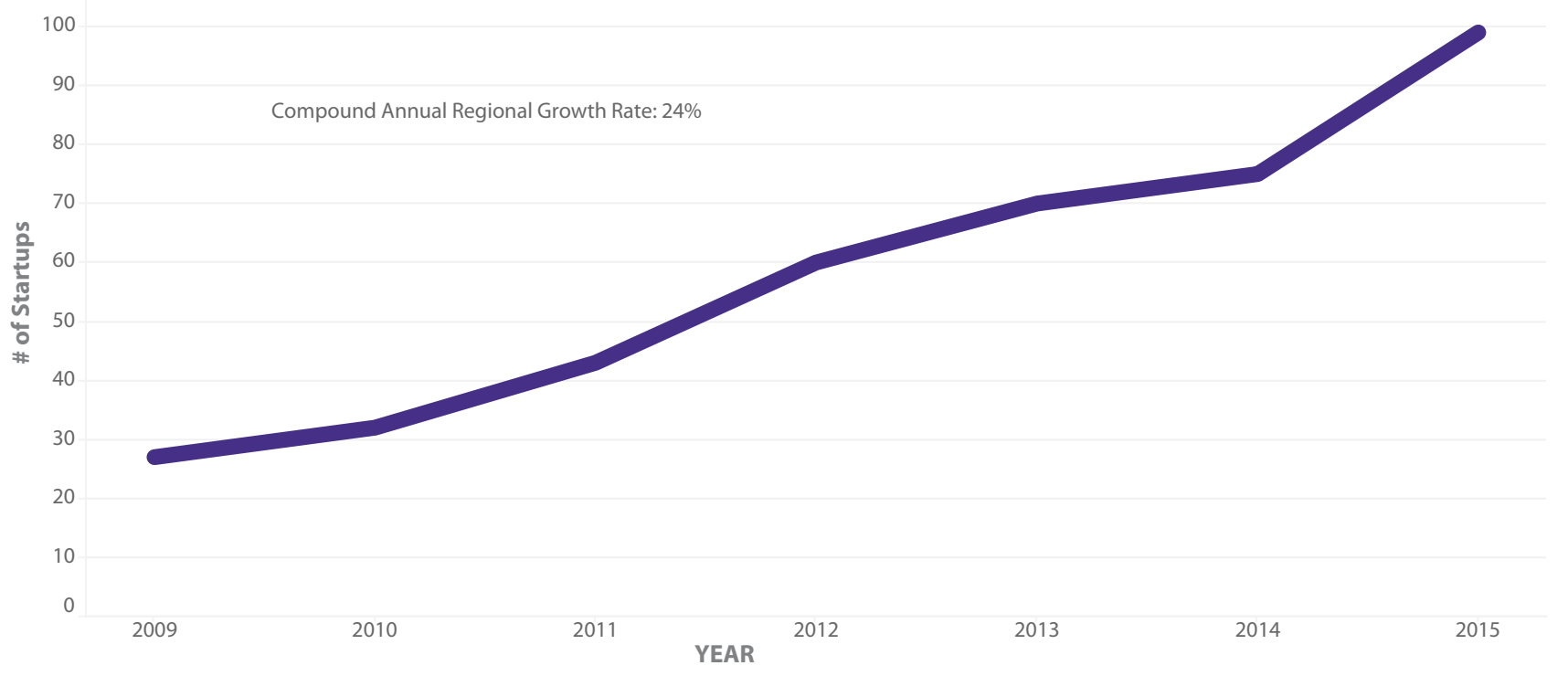

Note: Data shows tech start-up ventures as reported by founders of active start-ups during date of survey. Data of start-ups founded in year 2016 was not included in this figure because the survey was carried out in mid-2016, which was not comparable with all previous data from complete years. 
On average, start-ups in Beirut have 1.8 founders and each founder has launched 1.3 start-ups. This is consistent with other early to middle stage ecosystems, when serial entrepreneurs begin to feature.
Founders are predominantly male, and founders are twice as likely to focus on business than technical functions, with 40 percent doing both simultaneously (see Figure 2.3).

FIGURE 2.2 TIME TO COMPLETE PROCEDURAL TASKS IN LIFE CYCLE OF A

\section{START-UP ACROSS REGIONS}

\section{COUNTRY}

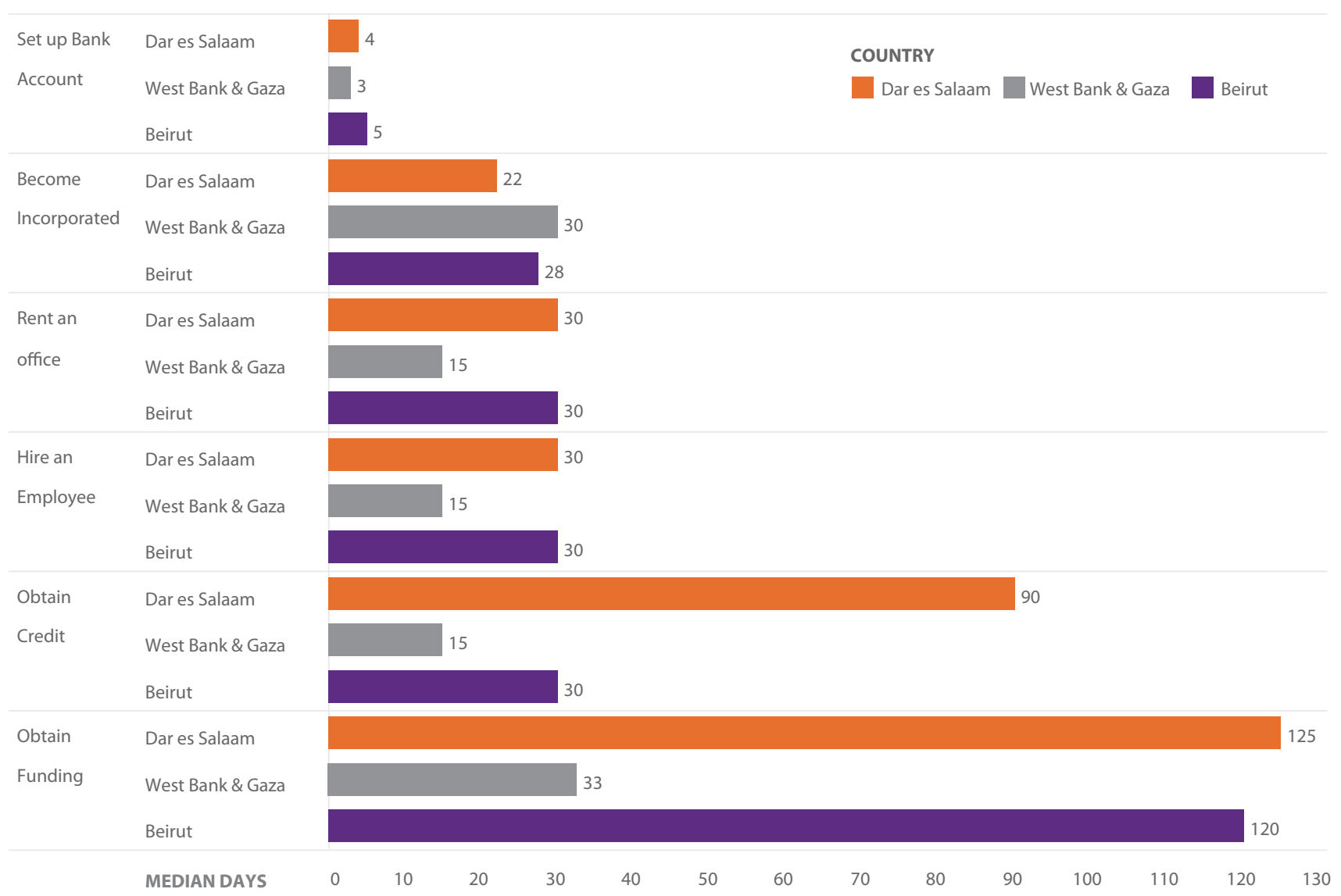

Note: Measurements refer to Dar es Salaam (Tanzania), Beirut (Lebanon) and West Bank \& Gaza start-up ecosystems

\section{FIGURE 2.3 GENDER DISTRIBUTION AND JOB FUNCTIONS OF FOUNDERS}

\section{Gender Distribution of Founders}

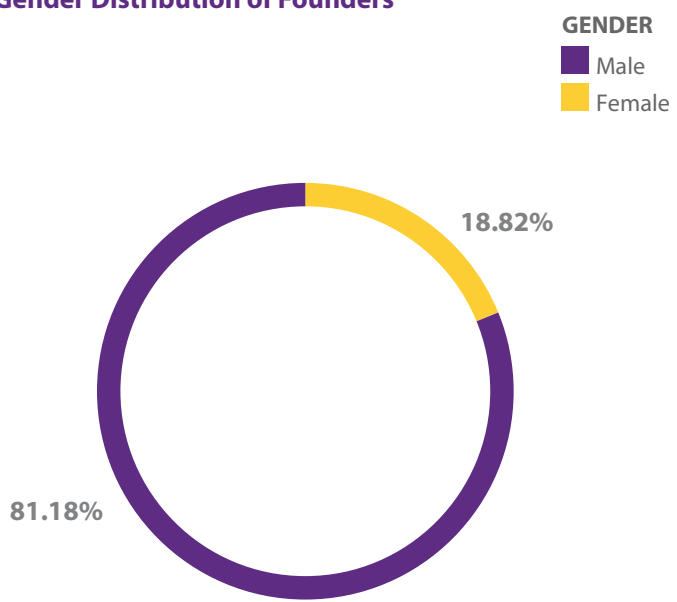

Job Functions of Founders

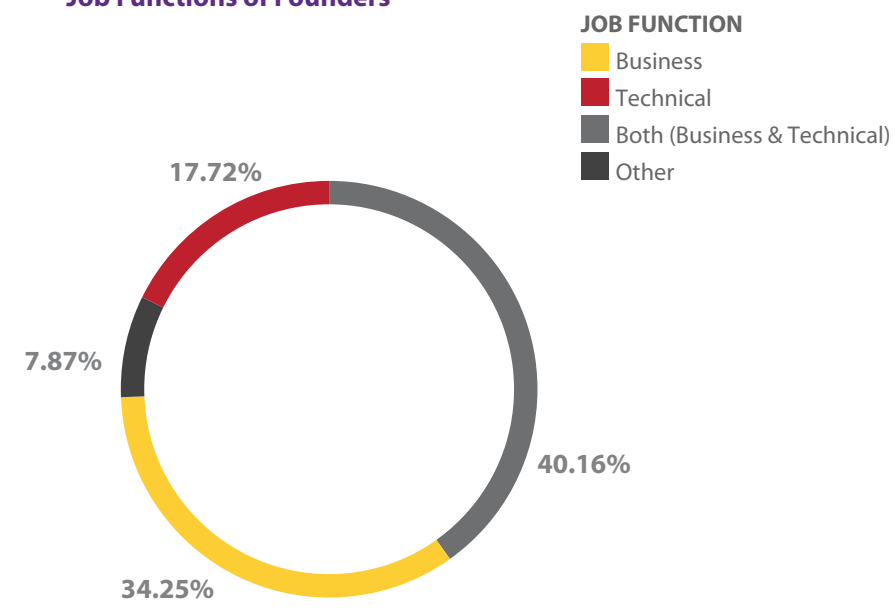


Founders are 29.8 years old on average at the time of founding (see Figure 2.4). ${ }^{12}$ This puts Beirut on par with mid-stage ecosystems, such as Bogota, and mature ecosystems, such as New York, which has an average age of founders in the late 20 s and early 30s and confirms the maturing stage of the ecosystem (see Figure 2.4).

\section{FIGURE 2.4 AVERAGE AGE OF FOUNDERS}

Average Age of Founders Across Various Regions

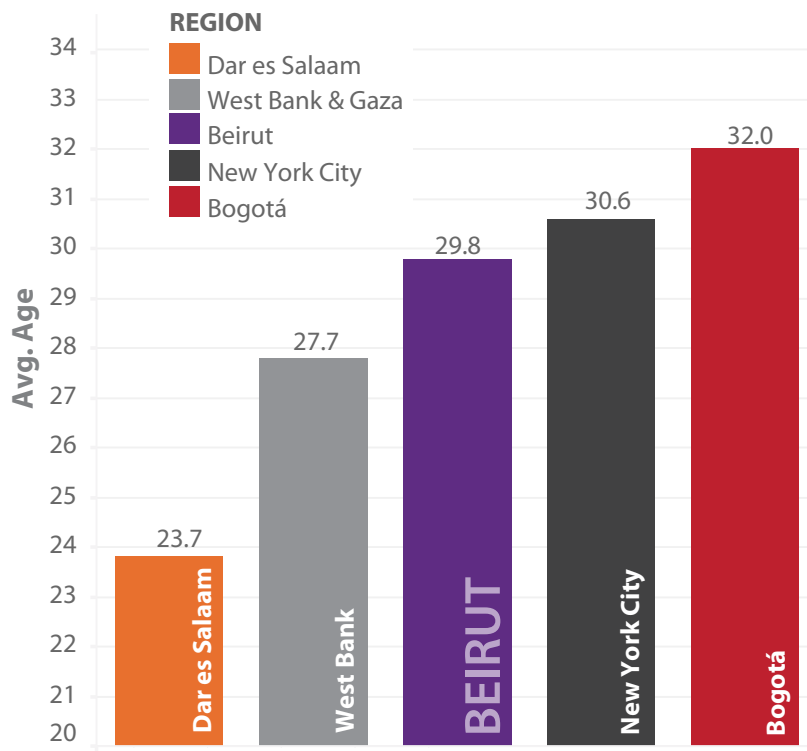

Age Distribution of Founders in Lebanon

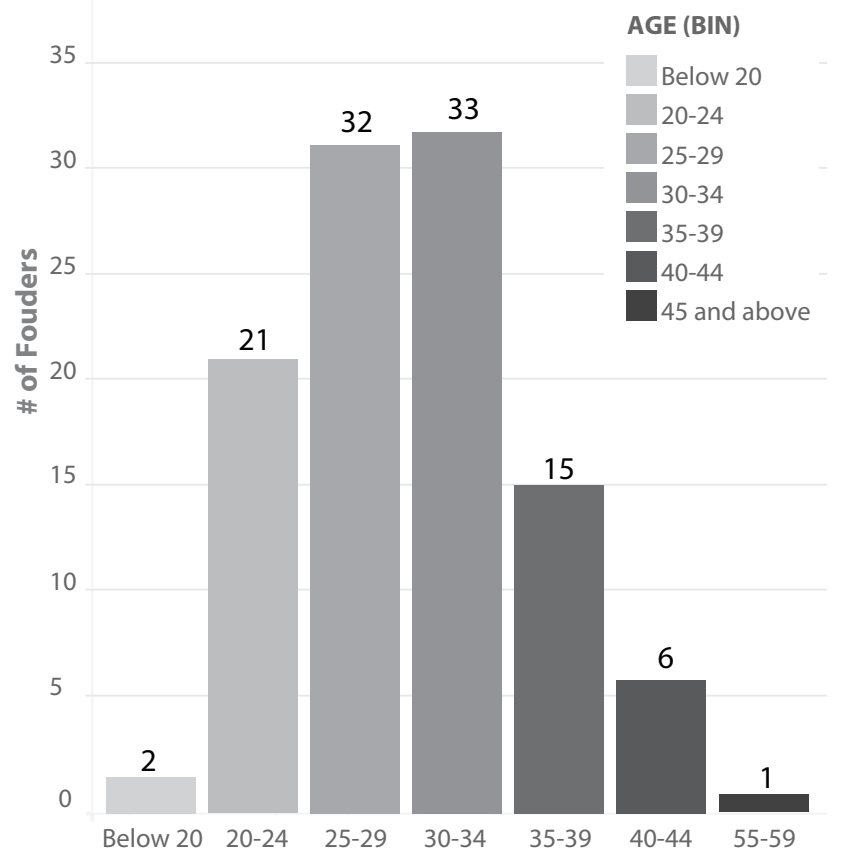

Note: Based on 110 responses (out of 255, 43 percent) that specified the age of founders.

\section{Skills}

Founders in Beirut are typically highly educated and have had some professional experience before they start their ventures. However, most of this professional experience is in entry-level positions, which does not provide all the needed business acumen for start-up management.

Educational levels are especially high among founders in the context of Lebanon, ${ }^{13}$ with over 90 percent having a university degree and over 50 percent having a postgraduate degree (that is, masters, professional, ${ }^{14}$ or doctorate). Somewhat surprisingly, there is little difference in the educational background of funded founders compared with the general population of founders (see Figure 2.5), but perhaps this is to be expected given that the general cohort of founders in Beirut is highly educated and the percentage of founders with graduate degrees is comparable with more mature ecosystems such as Singapore or New York City (see Figure 2.6).

\section{FIGURE 2.5 EDUCATIONAL LEVEL OF FOUNDERS IN BEIRUT}

\section{Highest Degree Earned by Founders at Time of Founding}

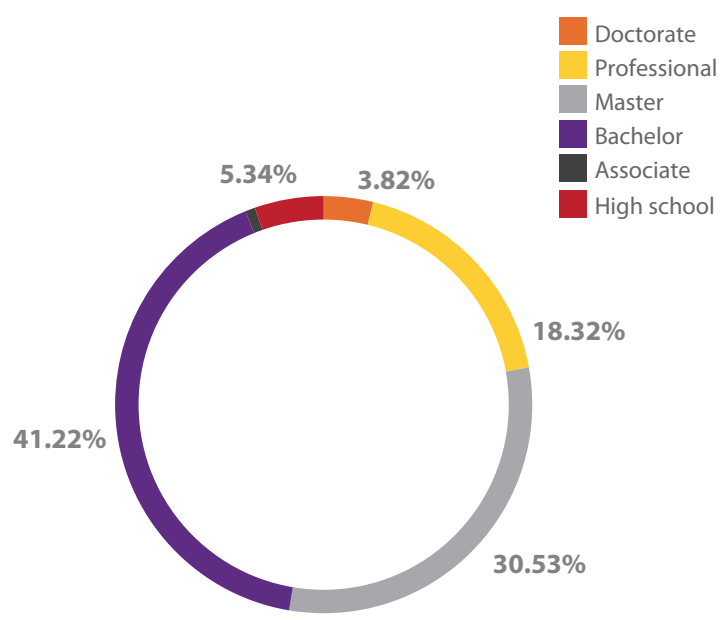

Highest Degree Earned by Funded Founders at Time of Founding

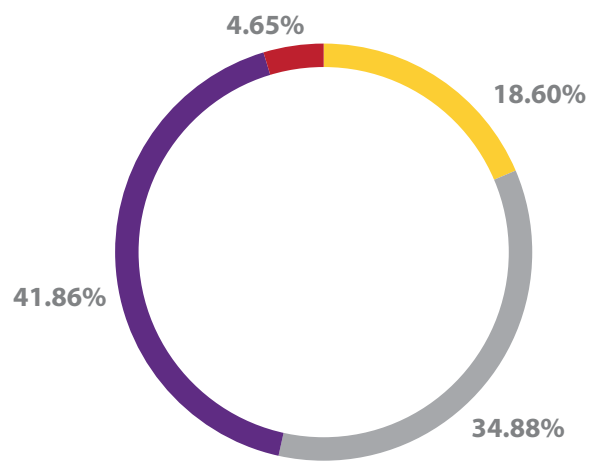


The majority of founders (51 percent) have a degree in science, technology, engineering or mathematics (STEM), 14 percent had a degree in business, and 13 percent had both STEM and business degrees. ${ }^{15}$ Fifty-two percent of STEM degrees were master's or higher. Indeed, founders that have successfully obtained funding in Beirut were slightly more likely to have specialized in business (see Figure 2.7).

The average founder in Beirut has 7.8 years of work experience with no more than 2.7 companies. This work experience is similar to other emerging and middle stage

\section{FIGURE 2.7 EDUCATIONAL EXPERIENCE OF FOUNDERS IN BEIRUT}

Educational Experience of Founders at Time of Founding
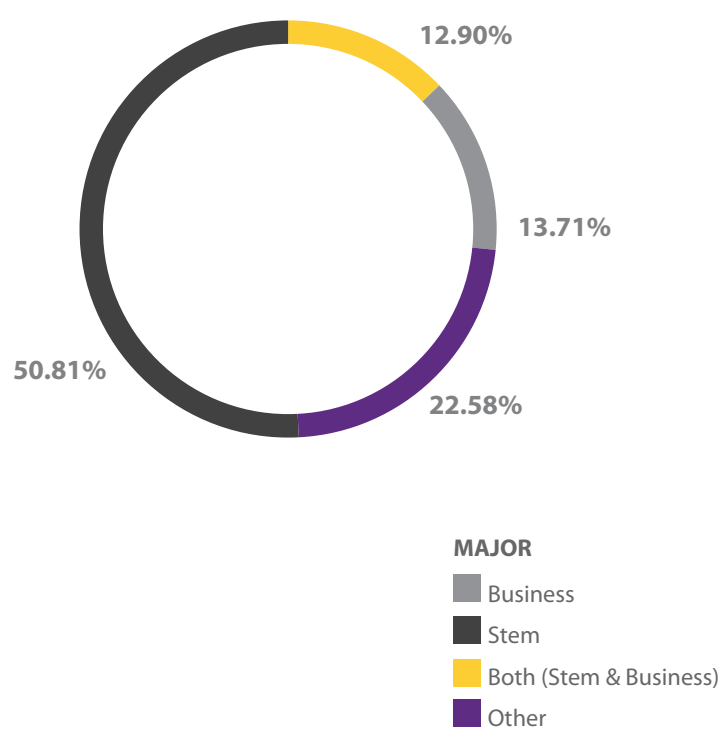

Educational Experience of Funded Founders at Time of Founding

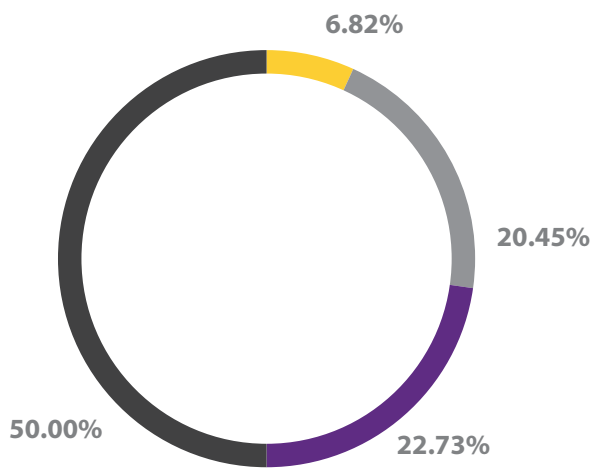

ecosystems. In a much more mature ecosystem, such as New York City, the experience of founders is higher, with 9.9 years in 3.25 companies.

The largest category of previous function is analyst, with 29 percent of founders with such experience. ${ }^{16}$ While only 22 percent of founders have experience in a managerial role, more than half of founders have had business experience, with slightly more than a quarter of founders experienced in both business and technical roles (see Figure 2.8).

\section{FIGURE 2.8 PREVIOUS FUNCTION AND ROLE TYPE OF FOUNDERS IN BEIRUT}

Previous Functions of Founders at Time of Founding

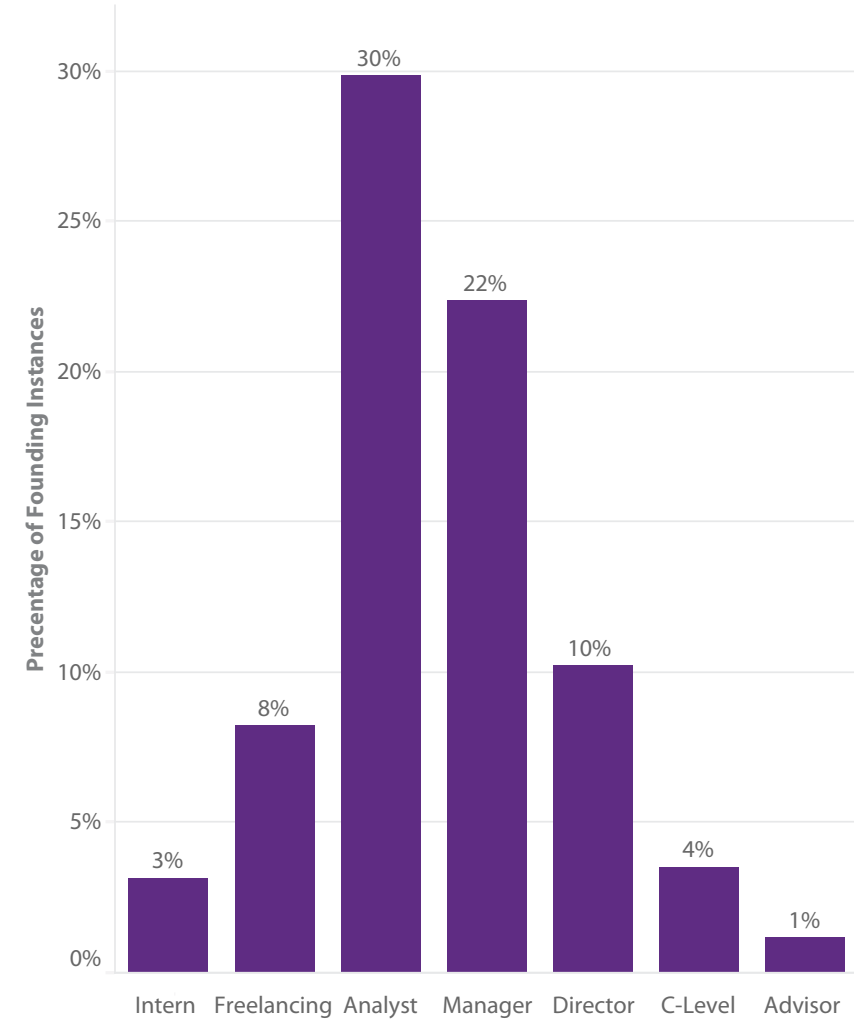

Previous Role-Type of Founders

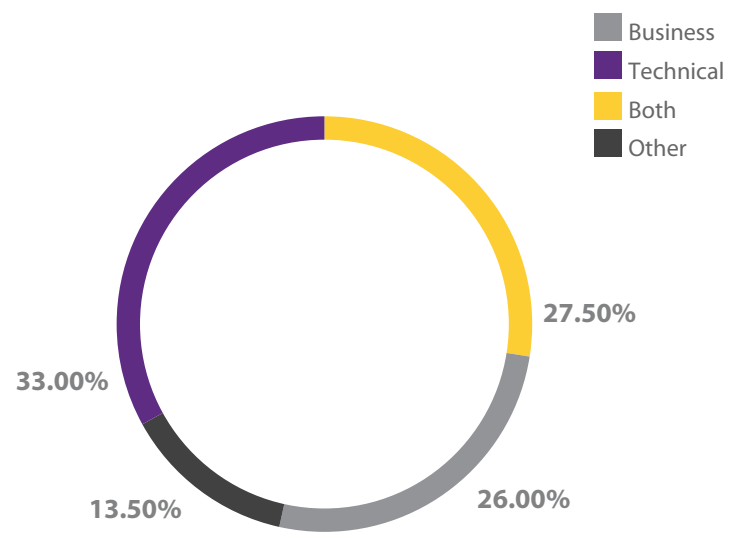


FIGURE 2.6 HIGHEST DEGREE EARNED BY FOUNDERS AT TIME OF FOUNDING

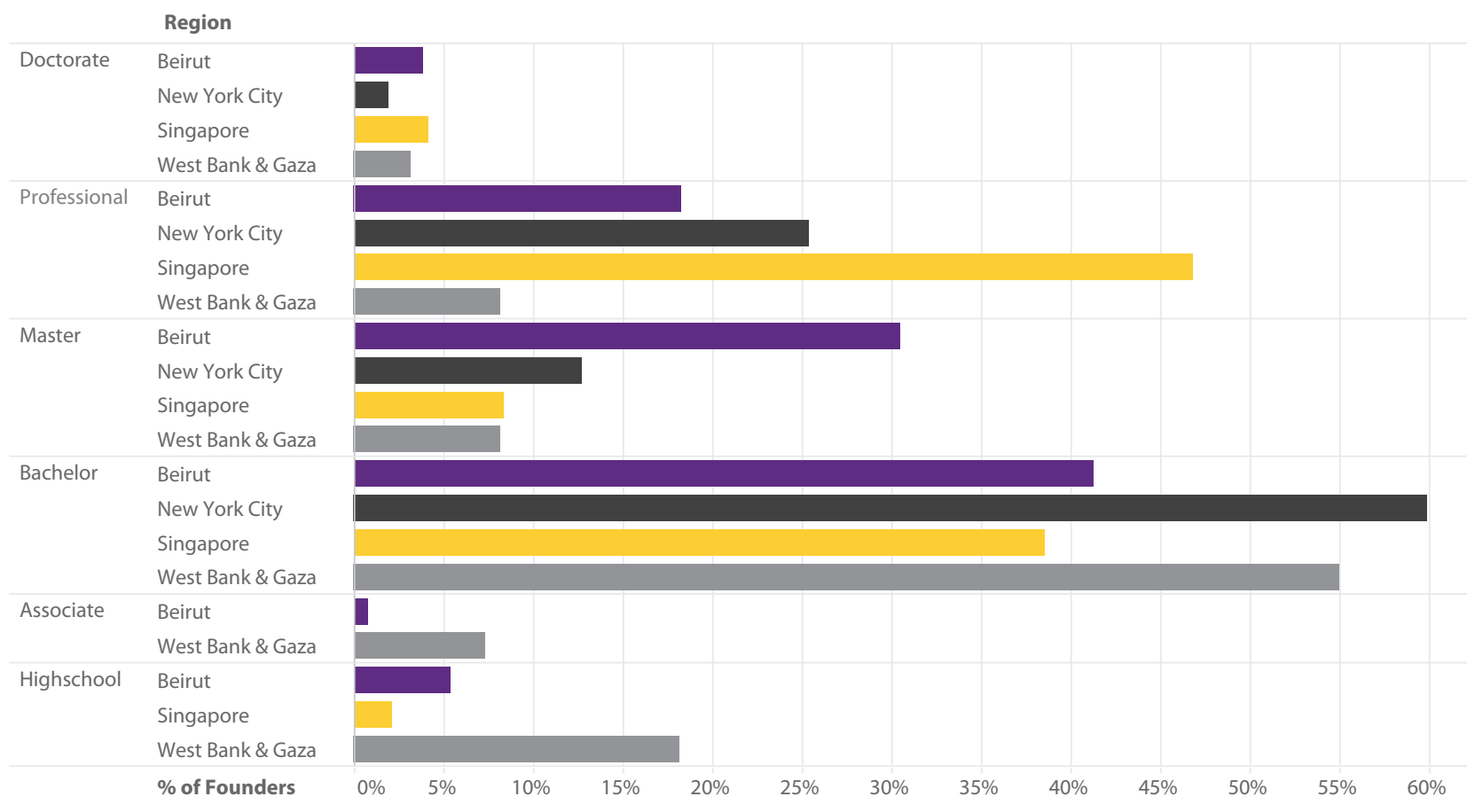

\section{Supporting Infrastructure for Entrepreneurship}

Consistent with the ecosystem's maturity, the supporting infrastructure for start-ups in Beirut's ecosystem is passed its initial growth phase but still maturing. The two main elements of the supporting infrastructure analyzed are accelerators and incubators, terms that are used interchangeably in this report (see Box 2.1), and mentors.

\section{Accelerators}

Accelerators support start-up growth by providing skills and networks of connections. Previous research from the World Bank shows that accelerators have a key role in supporting the community of start-ups that generate the ecosystem, providing the necessary social connectivity among entrepreneurs and other ecosystem stakeholders (Mulas, Minges, and Applebaum 2015). Research from the Aspen Institute also suggests that accelerators have a positive impact in supporting early stage ventures by providing access to a network of mentors and capacity building, particularly regarding business skills and acumen (I-DEV International 2014; Baird, Bowles, and Lall 2013; and Roberts, Lall, and Baird. 2016).

There are 10 unique accelerator programs that have been attended by start-ups in Beirut's ecosystem (see Figure 2.9). ${ }^{17}$ These accelerators have accelerated a total of 28 start-ups. Three of these accelerators are international (i.e., not based in Beirut), showing the

\section{BOX 2.1 ACCELERATORS AND INCUBATORS}

Although the dataset and analysis does not differentiate between incubators and accelerators, there is a difference in their definition:

Accelerators support entrepreneurs and start-ups in the early stages of development and they are often comprised of the following features: (i) a highly competitive and open application process for entrepreneurs, (ii) provision of small amounts of seed investment, (iii) a focus on small teams rather than individual founders, (iv) intensive support for a limited period of time (usually 3-6 months), with active mentorship and networking, and (v) collaborative work among start-ups through cohort or classes of start-ups.

Incubators are spaces that support start-ups by providing office space and administrative support services. The most typical services are legal, recruiting, IT, accounting, public relations and pooled buying programs. In addition, incubators may also provide coaching, mentorship, and help with access to funding on an informal basis. Startups pay rent (which is usually below the market rate) for the office space and normally a time limit is not set for start-ups staying in the incubator (the average length of stay ranges widely from 18 months to five years). Some incubator providers may ask for a share of future profits or require a minority stake in the start-up as a prerequisite for access to the incubator.

Source: Mulas, Minges, and Applebaum 2015. 
connection of Beirut's ecosystem to external resources in other ecosystems (see Community section). Accelerator programs were very limited in Beirut until 2015, when Circular 331 funding resulted in a substantial increase of programs for Beirut's startups. Three out of four accelerator programs located in Beirut (UK-Lebanon Tech Hub, Altcity Bootcamp and Speed at BDD) received funding from Circular 331.

Two-thirds of accelerated start-ups were funded, while only one-third of unaccelerated start-ups were funded, that is, startups supported by accelerators are twice as likely to receive funding as those that do not. This means that the acceleration multiplier for funding probability is $2 .{ }^{18}$ This is normal for nascent ecosystems, where accelerators are crucial in increasing the quantity of funded start-ups in the ecosystem's pipeline. Preliminary analysis of similar measurements in more mature ecosystems, such as New York City and Santiago, shows that this ratio reduces to become closer to 1 as the funding ecosystem matures and accelerators are no longer the gatekeepers to investment networks.

Of start-ups that were funded, accelerated start-ups received an average of 1.38 investments, while unaccelerated start-ups received an average of 1.45 investments, ${ }^{19}$ an acceleration multiplier of investment $0.95 .^{20}$ If we interpret the number of investments a start-up receives as a signal of its quality, this

\section{FIGURE 2.9 ACCELERATOR PROGRAMS ATTENDED BY START-UPS IN BEIRUT}

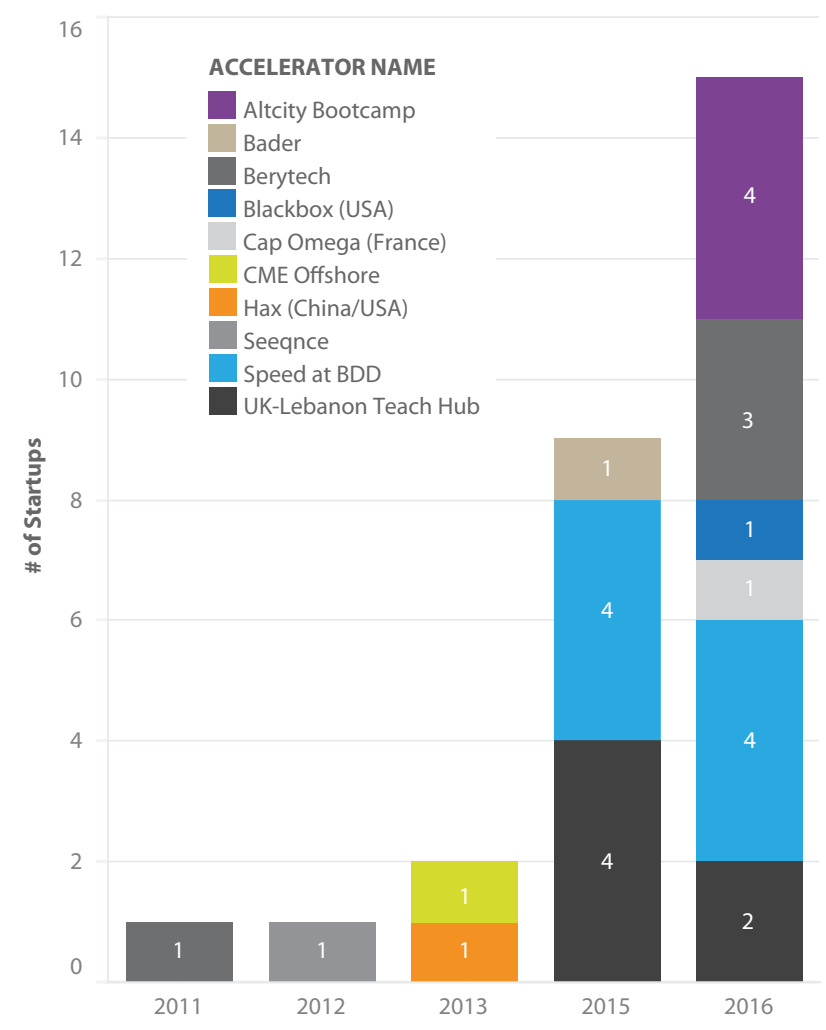

Note: no acceleration occurrences were reported in 2014. suggests that accelerators in Beirut are not having a meaningful impact in improving the quality of start-ups. In fact, of the 55 start-ups that were funded, more (39) were unaccelerated than accelerated (16). Half of the accelerated start-ups received funding in the same year that they participated in the acceleration program

Using these numbers, the effectiveness of accelerators in Beirut's ecosystem may be estimated by calculating a ratio of quality, as represented by the acceleration multiplier of investment $(0.95)$ to quantity, as represented by the acceleration multiplier for funding probability (2), which results in a ratio of 0.48 . This is consistent with the quality to quantity ratio from other middlestage ecosystems, such as Cairo, which also has a ratio of less than 1, while mature ecosystems such as New York City will have a ratio of more than 1 (see Figure 2.10).

These results support the conclusion that it is difficult to access venture funding without attending an accelerator program, even though these programs do not meaningfully improve the quality of start-ups they host compared to unaccelerated start-ups. Nevertheless, half of accelerated start-ups received additional investment in the years after graduating, indicating that there is plenty of capital available in the ecosystem regardless of the quality of start-ups in the pipeline. This is unsurprising given Circular 331's role in catalyzing investment availability (see Program in Focus).

\section{FIGURE 2.10 ACCELERATOR'S QUALITY/ QUANTITY RATIO (SELECTED CITIES)}

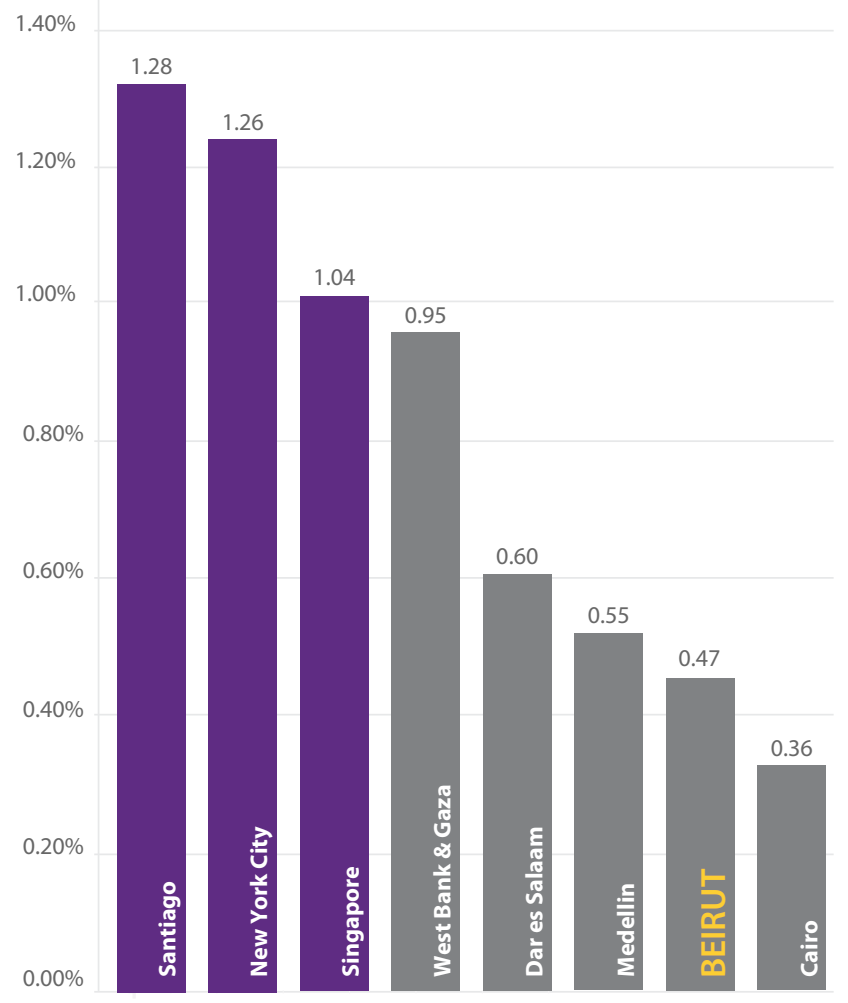




\section{Mentors}

Mentorship is a knowledge transfer mechanism for entrepreneurs to acquire business acumen, understand the unspoken rules of start-up challenges, and access networks of talent, knowledge, and resources. Mentors need to be knowledgeable and experienced. A study for the U.K. government found that the most important characteristic of a mentor is proven business success in the area of work and network of contacts (BMG Research and Galli 2013). Mentorship relationships were found to often develop informally through a preexisting relationship. For example, acceleration and incubation programs typically assign start-ups formal mentors to assist them for a designated period of time. Research from Endeavor Insight shows that top performing start-ups have much higher support from mentors. ${ }^{21}$

In Beirut, 20 percent of founders received mentorship from a total of 53 mentors. This mentorship tended to occur on a one-to-one basis and generally lasted about one year. Unlike other ecosystems, such as Tanzania's, Beirut does not currently possess "supermentors" associated with accelerators to mentor batches of entrepreneurs, indicating an opportunity to catalyze the mentorship ecosystem by creating more formalized programs.

\section{Groups and Events}

In addition to accelerators and mentors, groups and events are also a mechanism for support and knowledge dissemination. $\mathrm{BDL}$ Accelerate is a key event in the ecosystem, bringing together both foreign and domestic players. Other important events attended by founders were hosted by The World Bank, ${ }^{22}$
Berytech, and the IFP (International Fairs and Promotions) Group. The top groups that founders in Beirut claimed to be members of were Endeavour, Tripoli Entrepreneurs Club, and Bootcamp Sal.

\section{Investment}

The value of investors extends beyond the money they provide. Early stage investors are often valued both for their networks and for their experience and subject area expertise, hence the phrase "smart money." This report considered all organizations that invest in high-growth start-ups, venture capital firms, angel investors, and other individuals.

Forty-three investors were recorded in Beirut. About half of these were venture capital firms and the other half angel investors. They made a total of 58 investments in 35 startups, and all investments were identified as equity financing. The median number of start-ups invested in per investor was 1, but with several notable outliers. Speed@BDD invested in nine different start-ups, Berrytech in four, and Middle East Venture Partners (MEVP) in three.

Although there is a significant fall in the number of startups funded in their first year compared to subsequent years, a substantial number of start-ups receive funding in the second year and beyond. This indicates that the ecosystem has developed beyond the nascent stage and is maturing into a middle stage ecosystem. Furthermore, the median investment amounts in later years of existence is encouraging in that they are exceeding $\$ 100,000$ (see Figure 2.11).

\section{FIGURE 2.11 MEDIAN INVESTMENT AMOUNT}

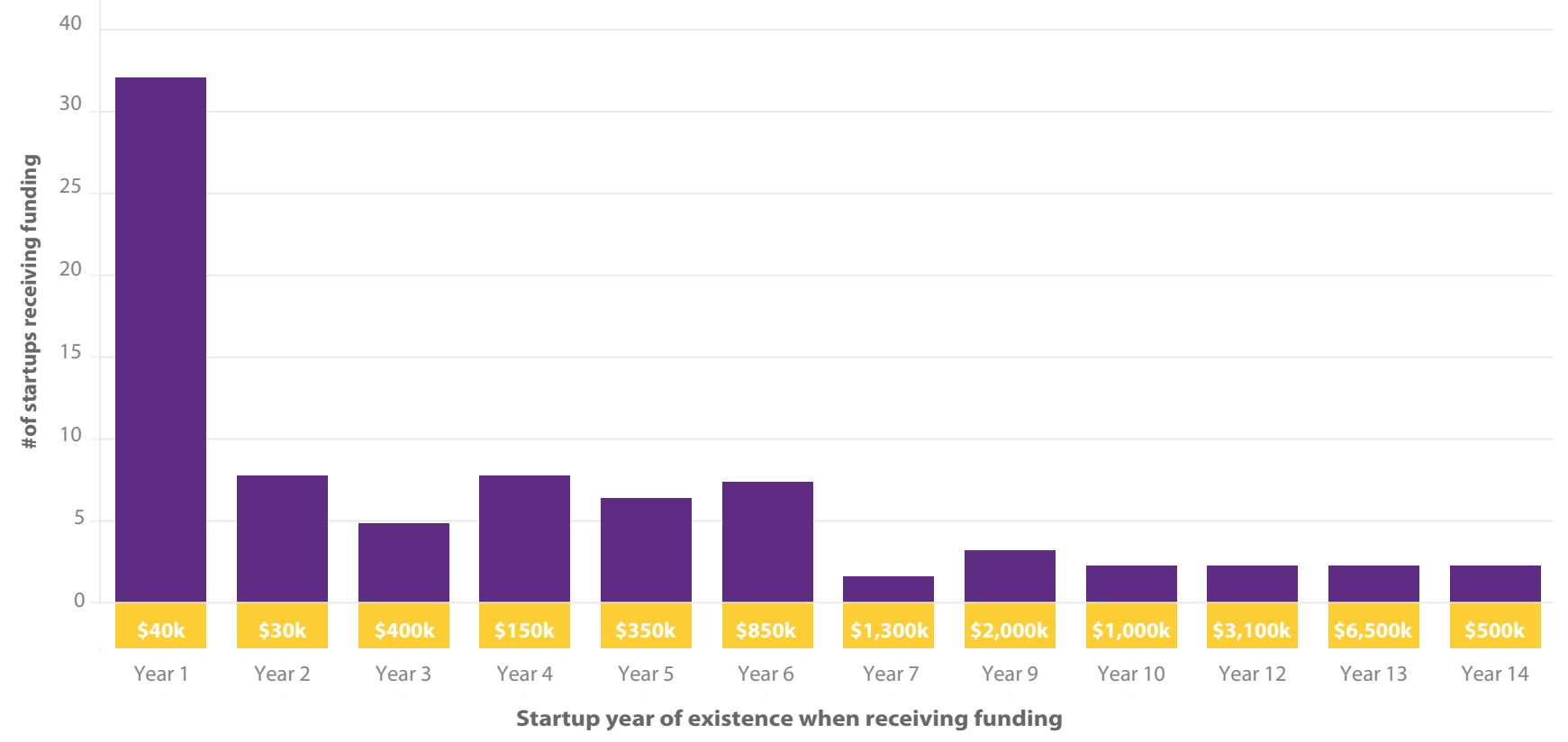

Notes: Only three start-ups received investment more than once; No funding was reported by startups in year 11 of existence. 


\section{Community}

Start-up ecosystems operate as communities, where knowledge spillovers and access to resources flows through a network of embedded connections (see Figure 2.12). The tighter and more connected an ecosystem, the more efficient is the flow of knowledge and access to resources. The less connected it is, the less effective is the ecosystem in spotting talent and nurturing potential ventures into successful start-ups.

Connectivity matters because the success of start-ups is impacted by their network and access to other ecosystem stakeholders and their networks (Mulas, Minges, and Applebaum 2015). In Beirut, the main cluster of start-up activity revolves around BDL Accelerate. The Beirut ecosystem has also begun to pull in more global networks, such as that from Startup Weekend or the University of Pennsylvania (see Figure 2.13)).

The most prominent network in Beirut is BDL Accelerate, which is consistent with the role the Bank du Liban has played in the ecosystem through Circular 331 and complementary initiatives. Through first and second-order connections, the Beirut ecosystem connects with international clusters such as Startup Weekend and the University of Pennsylvania, which presents the potential to access financial and intellectual resources not available in the domestic market. This is consistent with the background of Beirut startup founders, many of whom are well-connected internationally and often have dual or triple nationalities with other countries. This is a unique feature of the Beirut ecosystem and of Lebanese society in general, which has strong international connections through its diaspora and transient populations.

The community of Beirut's ecosystem is consistent with its nascent stage with low density and a limited number of clusters. ${ }^{23}$ Higher density and more clusters allow entrepreneurs to connect to knowledge and resources through other actors in the ecosystem. The less dense the ecosystem is, the more difficult it is for a founder to find their way to mentors, investors or other relevant knowledge or resources required for their venture. Clusters serve as multipliers of density, helping founders leapfrog orders of connection (for example, connections that in other case are $a 5^{\text {th }}$ or $7^{\text {th }}$ order connections, that is, the founder is connected through 5 or 7 connections to the target person, become a $2^{\text {nd }}$ or $3^{\text {rd }}$ order connection, where the founder is connected through two or three people to the target connection).

When comparing the density and clusters of the community with those of more advanced ecosystems (see Figure 2.14), Beirut features low density with one cluster in formation and some potential sub-clusters. Cairo or Medellin have already evolved into highly connected clusters driving connectivity in the ecosystem.

\section{FIGURE 2.12 GROWTH OF FOUNDERS AND CONNECTIONS IN BEIRUT}

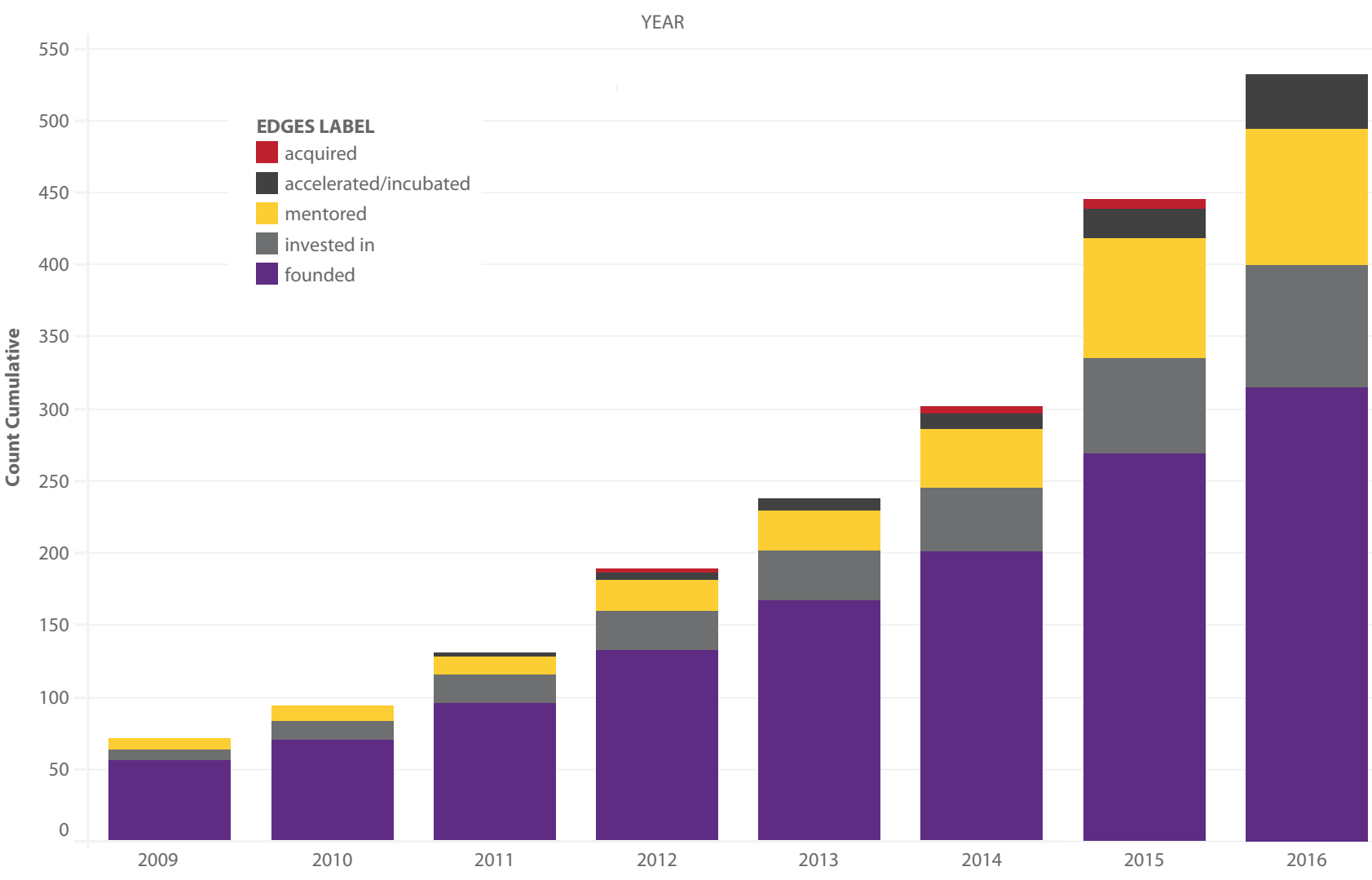




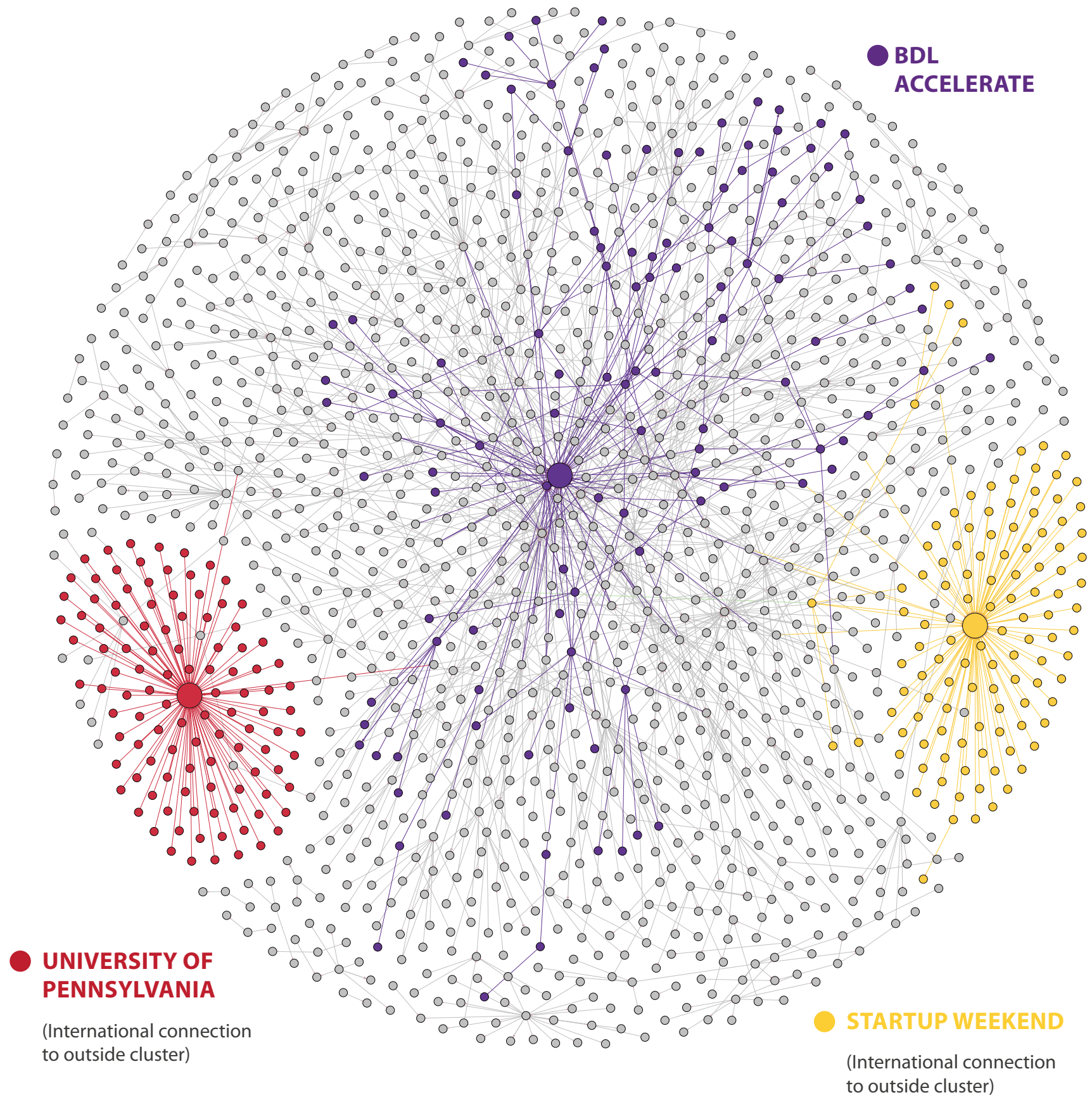

Note: This graph highlights BDL Accelerate (purple),

Startup Weekend (yellow), and the University of Pennsylvania (red). 
FIGURE 2.14 PROGRESSION OF ECOSYSTEM CONNECTIVITY

\section{MEDELLIN}

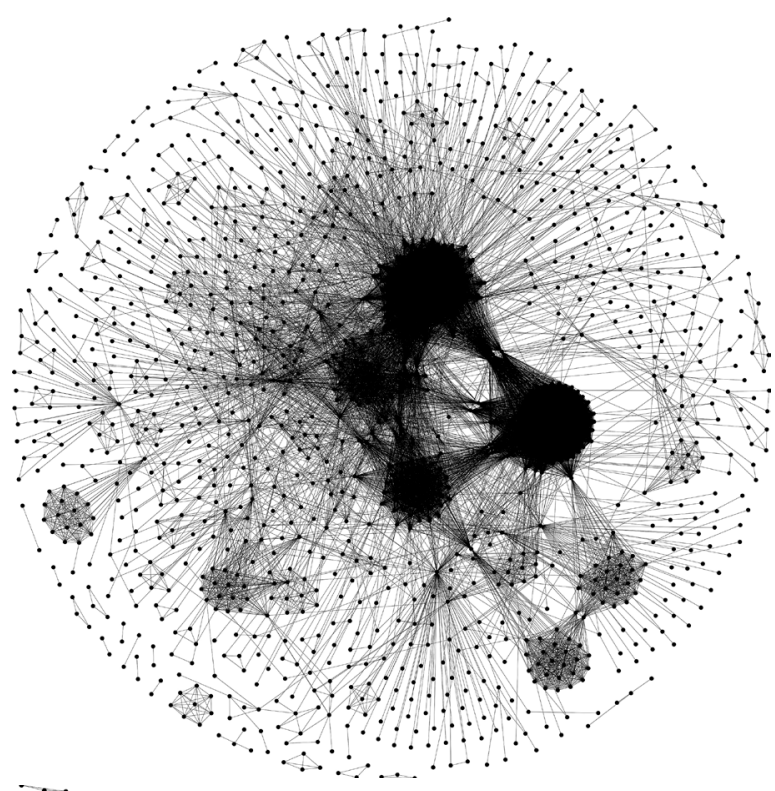

CAIRO

Note: Network graphs were created by taking all the people in the ecosystem and creating edges to all other people they were directly or indirectly connected to in order to exaggerate the effects of clusters for illustration purposes. Because this treatment visualizes the influence of edges seen in Figure 2.13 by counting them more than once, the density of the clusters and the overall graph will appear different from Figure 2.13, where each edge is represented only once, even though the underlying data is the same. 


\section{Start-up Success Factors}

Start-up success is difficult to determine as tech ventures operate in a fast-paced environment under continuous change. To analyze factors that have determined start-up success, this analysis identifies two moments in the growth of start-ups. We consider "short-term success" as when a venture obtains funding from an outside investor and "long-term success" as when a venture hires employees consistently (this assumes continuous growth as the talent-knowledge assets of the start-up grow).

\section{Factors of Short-term Success}

The most significant factor for raising funding in Beirut is to be highly connected to other stakeholders. Given the early stage of the ecosystems community (see Community section), there are very few clusters available for start-ups and very few start-ups inside these clusters. Those start-ups that are inside these clusters have access to investors and can leverage those connections to obtain their first funding. Once start-ups have become part of one of these clusters and have obtained funding, they increase substantially their network of investors, reinforcing their positioning in relation to future investments. Older startups (those that have survived over time) are also more likely to raise funding.

These results suggest that there appears to be a main cluster in the investment ecosystem, and the majority of activity is occurring in this maturing cluster. This hypothesis is supported by a comment from a survey respondent who stated that, "I wish it wasn't centralized in the limited number of VCs and banks that are all in one bundle and interconnected. Some competition between the VCs and the programs would push them to provide better services."

\section{Factors of Long-term Success}

The most significant factors for long-term success (that is, hiring employees over time and continuing to do so) are: a) obtaining an investment, and b) having additional work experience. Participation in acceleration programs and mentorship relationships have no significant effect on longterm hiring probability. Moreover, serial entrepreneurs in Beirut are also less likely to hire consistently, suggesting that start-ups have difficulties in scaling up, staying in a continuous early stage cycle. There is no significant impact of educational factors on job creation.

These results suggest that the support infrastructure of the ecosystem (for example, accelerators, mentorship) is not supporting scale-up of start-ups adequately, either because quality is low or because their impacts are not yet visible. However, the low probability that serial entrepreneurs will mature their businesses suggests that there may be a lack of general skills available in the ecosystem to transform ventures into sustainable businesses.

FIGURE 2.15 SHORT-TERM SUCCESS

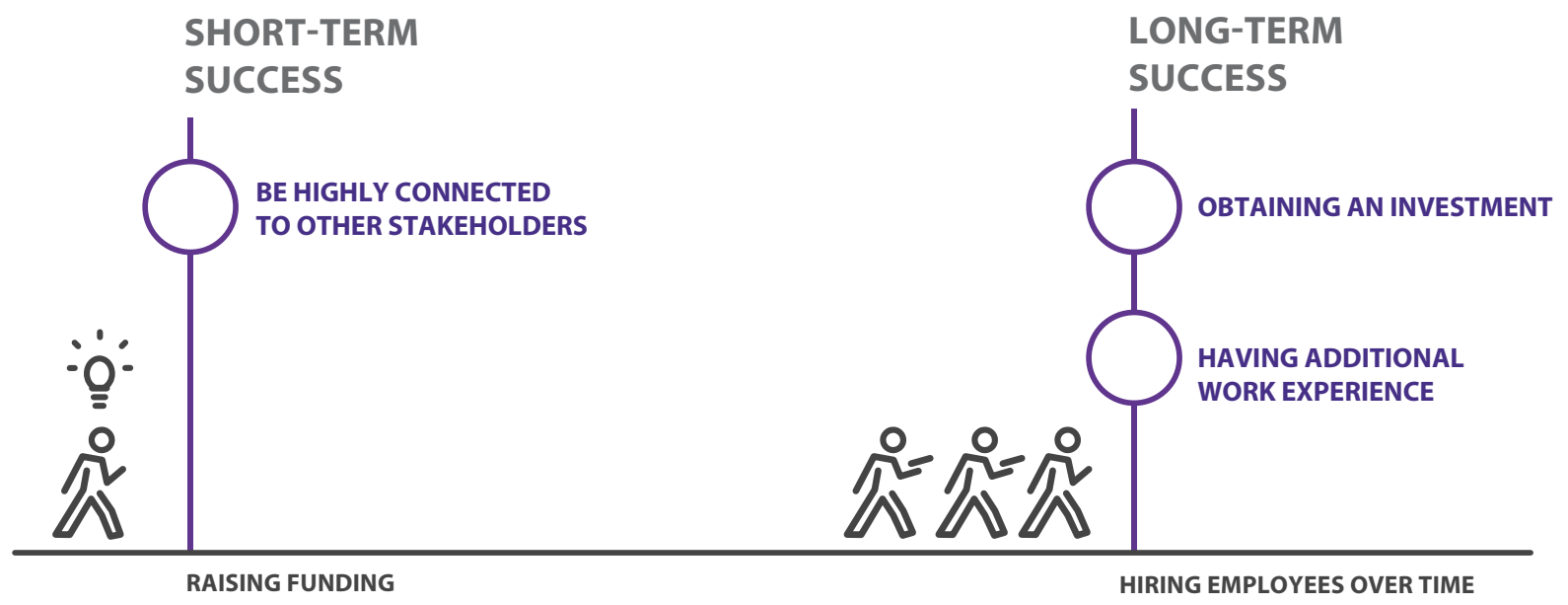




\section{Gap Analysis and Policy \\ Recommendations}

\section{Summary of Gap Analysis and Stage of Ecosystem}

The evidence from our analysis points to the conclusion that the start-up ecosystem in Beirut is an early advancing (middle stage) ecosystem (see Table 3.1).

TABLE 3.1 DEVELOPMENT STAGE OF ECOSYSTEM (PER AREA AND OVERALL)

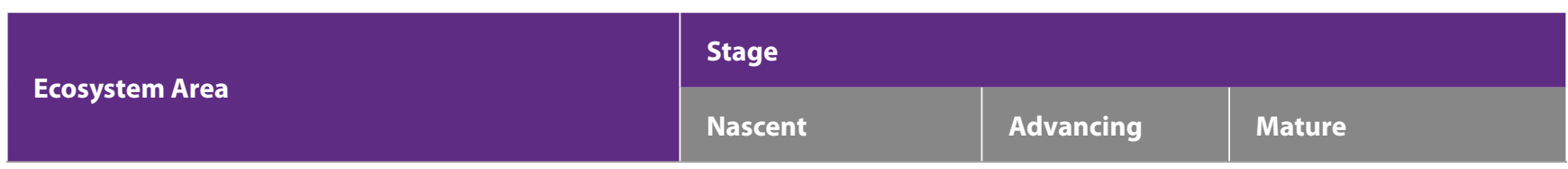

\begin{tabular}{|c|c|c|c|}
\hline & Community & 0 & \\
\hline 奌 & Skills & & 0 \\
\hline 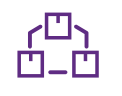 & Supporting Infrastructure & 0 & \\
\hline$\frac{88}{111}$ & Investment & & 0 \\
\hline \multirow[t]{2}{*}{ 色 } & Constraints & 0 & \\
\hline & OVERALL & & 0 \\
\hline
\end{tabular}

There are multiple gaps that can be addressed through policy action and support. The community is immature with only one functioning cluster, and as such start-ups are constrained in the diversity of resources they can access. Events and community building appear to have been catalyzed by programs of the Banque Du Liban (BDL), the Central Bank of Lebanon (BDL Accelerate and Circular 331), and donor and government action still drives a large number of activities in the ecosystem. There is an incipient number of support programs for entrepreneurs (for example, accelerators) but they do not yet seem to be providing services of sufficient quality to support sustainable ventures. There is a lack of experienced entrepreneurs and, combined with the limited availability of quality mentorship, these factors reduce the availability of young talent to complete the cycle of successful ventures. There is a potential bubble of start-up ventures being funded by the abundance of available seed funding, which may be distorting the ability of the ecosystem to select the best start-ups and generate success stories that are sustainable over time. ${ }^{24}$ Finally, the sustainability of the current level of access to funding, which is fueling the ecosystem, is not ensured if Circular 331 is phased out (see Box 3.1). 


\section{Policy Recommendations}

Table 3.2 summarizes the policy recommendations for the Beirut ecosystem, based on the key gaps and constraints identified.

TABLE 3.2 POLICY RECOMMENDATIONS

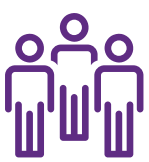

Community
Strengthen coordination mechanism and ecosystem support program with stakeholders
Expand cluster connectivity, coordinate private and public action and increase density of connections among all stakeholders

Expand ecosystem community to traditional industries and absorb international connectivity talent connectivity, connect with domestic

corporate nontech sectors
Address practical business acumen gaps, provide pipeline of talent for start-up scale-up and include lower income/educated population through rapid skills training programs and include public education programs

Address lack of sufficient number of quality mentors and strengthen support services accelerators and attraction of international talent (as mentors, entrepreneurs or capacity builders) to the ecosystem

Infrastructure

Assess quality of start-up funding and prepare phase out of Circular 331 introducing private sector funding
Address potential bubble of start-ups and distortion of investment market, and ensure sustainability of funding

Investment

Address processes constraints (for example, access to loans and funding)
Reduce constraints for start-ups incorporation and operationalization

Constraints

These recommendations only address short-term actions to support the Beirut ecosystem. Policy makers should constantly monitor the ecosystem (which can be done through the coordination mechanism once in place) and iterate the policy approaches as needed and address new upcoming gaps or growth hurdles as they arise. As the ecosystem grows and evolves into more maturity, new needs will emerge and other specific policies may be more applicable.

\section{Community}

Strengthen coordination mechanisms and ecosystem support programs for stakeholders. Ecosystem coordination increases the effectiveness of community-building events and connectivity among clusters. Successful ecosystems, such as in Buenos Aires, or New York, have created different types of coordination mechanisms among stakeholders led by public policy actors (for example, municipal or government innovation agencies). These vary from stakeholders' roundtables to continuous consultation processes and support programs for public-private partnerships (PPPs) (ITIF 2017).

Beirut has multiple intermediaries and stakeholders with active programs (including Endeavor Lebanon, Berytech, Wamda, Lebanon UK Tech Hub, Alt City, and Beirut Digital District's (BDD) Speed@BDD, among others). However, these activities are not connecting different clusters of start-up founders as well as they could, suggesting a lack of in-depth connection. Better and wider coordination of stakeholders beyond BDL Accelerate and codevelopment of day-to-day events from multiple stakeholders (which can be catalyzed through public support) could help in developing more in-depth connectivity between clusters, programs, and mentors.

Increase absorption by the ecosystem of international talent, and improve connectivity with domestic corporate nontech sectors. BDL Accelerate has been successful in promoting Beirut's ecosystem and elevating Lebanon's brand as an incipient start-up hub in the region. It has also attracted 
international talent to Beirut, providing a window to connect the ecosystem to international talent beyond the already well-developed diaspora network. If they can be absorbed by the ecosystem, international talent and know-how is key to developing the ecosystem beyond its growing stage. Diaspora networks may provide an initial connection with international talent, but if diaspora talent is not retained, that connection will not provide a solid foundation for the ecosystem.

Israel's ecosystem developed specific programs to attract international talent (through multinationals and startup support programs) and develop the absorption of the ecosystem (through PPP programs connecting these talent and multinationals with domestic start-ups). This resulted in a close link between the Tel Aviv ecosystem and New York and Boston, fueling investment from VCs and talent exchange between these locations (indeed, many successful Israeli startups have active operational offices in Tel Aviv and the other US ecosystems) (ITIF 2017; and Getz, Daphne, and Goldberg 2016). Beirut could leverage BDL Accelerate's connections and its diaspora networks to further codevelop programs to support the ecosystem with international talent (for example, accelerator or skills training programs). This could be catalyzed with public support programs, similar to the way in which Israel and other ecosystems, such as Santiago in Chile or Seoul in Korea, have done (see policy recommendations on Skills below).

Finally, Beirut ecosystem could also expand beyond the tech sector, to include traditional industries. This was one of the key features of New York ecosystem success, for instance, which resulted in specialized start-ups with in-depth knowledge of industry niches and improved competitiveness of traditional sectors in the city, such as finance, media, advertising, and fashion (Mulas and Gastelu-Iturri 2016). Policy actions can be applied to catalyze industry-start-up innovation through open innovation and service codevelopment processes. For example, Paris has supported the corporate-start-up service codevelopment process through initiatives such as Data City Paris. ${ }^{25}$ In New York, the city used PPPs to catalyze sectorspecific accelerators for media and fashion, among others (Mulas and Gastelu-Iturri 2016).

\section{Skills}

Expand practical education in universities and through rapid skills training and public education programs. Public policies can catalyze and support both practical education programs to address the skills gaps in tech start-up ecosystems. Coding bootcamp methodologies (a rapid skills training methodology), are nascent in Beirut, ${ }_{1}^{26}$ but they have proven successful in quickly assessing market gaps and demands in tech start-up ecosystems. Moreover, these programs can serve to include the less-educated population into the ecosystem, by providing a basic set of skills connected to the ecosystem's needs. For instance, New York City's initiative to support rapid skills training programs resulted in General Assembly, one of the largest providers of bootcamps worldwide, which serves

\section{BOX 3.1 WHAT IS CIRCULAR 331?}

In August 2013, BDL announced Circular 331, injecting the potential of $\$ 400$ million into the Lebanese enterprise market. Circular 331 guarantees 75 percent of the banks' investments in the knowledge economy through direct start-up equity investment or indirect start-up support entities.

Local banks receive a seven-year interestfree credit from $B D L$, which can be invested in treasury bonds with an interest rate of 7 percent. In return, the bank commits to investing in the knowledge economy. Local banks can invest up to 3 percent of their capital in start-up support entities, funds, or directly into start-ups. BDL guarantees 75 percent of the investment, derisking it by mitigating the potential losses and reducing them to a mere 25 percent. Circular 331 is designed to diminish risk for the conservative local banks and does so by dictating the banks' portfolio diversification. A bank can invest up to 10 percent (of its 3 percent) in any one start-up, thus spreading the risk. BDL takes on 75 percent of the risk and only 50 percent of any profit made, making it attractive for local banks.

Source: $h$ ttp://2015.bdlaccelerate.com/everything-youneed-to-know-about-bdlcircular-331/

to address skills gaps ranging from entrepreneurship and business skills to specific coding and technical skills (see Box 3.2) (Mulas and Gastelu-Iturri 2016). Public policy programs can also help provide community spaces, and accelerators can also be supported to enhance their capacity to provide higher quality mentorship and training to start-up ventures with potential through their programs (in the case of accelerators) of related activities.

Additionally, public policies can catalyze the introduction of practical education programs for university students and address part of the gap in business acumen. Initiatives, such as Demola in Tampere, Finland ${ }^{28}$ and Jacobs Technion-Cornell Institute ${ }^{29}$ in New York, were created to address this specific gap in their ecosystems. In both cases, a practical project-based education is added for students to learning-by-doing with business. 


\section{Support Infrastructure}

Increase capability of mentors in accelerators and attraction of international talent (as mentors, entrepreneurs, or capacity builders) to the ecosystem. Support can also be provided to increase the capability of mentors (for example, through training and capacity-building programs). However, local capacity programs have limited impact beyond nascent stages of ecosystems. This is because there is a general lack of practical experience and knowledge among mentors and trainers since there have not been many cases of successful ventures that have been proven internationally (and whose founders are willing to be mentors or angel investors).

A way to address this lack of experience and knowledge is to attract international talent with such practical acumen. There are several support programs that can achieve this goal, ranging from events that gather international talent and connect it to the ecosystem, to more structural programs. While BDL Accelerate has led to a broader connection of the ecosystem's intermediaries (for example, community spaces, accelerators, and so on) with international talent and partners, these partnerships do not seem to have resulted in long-term mentorship relationships with entrepreneurs.

Santiago, Chile, followed a more structured approach, creating a program (Startup Chile) ${ }^{30}$ to attract international talent to the ecosystem. The program is in essence an acceleration-funded program for high-skilled international talent to conduct their ventures' initial stage in Chile. The program introduced specific activities to ensure knowledge spillovers between international talent and domestic entrepreneurs. For instance, international entrepreneurs were collocated in a coworking space with domestic entrepreneurs with a requirement that they provide capacity building and workshops on entrepreneurship and technical skills for domestic entrepreneurs. This mechanism has been emulated by other ecosystems, including the K-Startup Grand Challenge in Korea. ${ }^{31}$

\section{Investment}

Assess quality of start-up funding and prepare phase out of Circular 331 introducing private sector funding. Circular 331 has provided an influx of seed investment to the ecosystem resulting in wide availability of funding for early stage ventures. Though some procedural constraints still remain for access to finance (see Constraints policy recommendations), overall Beirut seems to have sufficient funding available for start-ups. However, two concerns are present. First, there are signs that the amount of funding availability may be larger than the capacity of the ecosystem to generate sufficient quality start-ups, resulting in the financing of nonsustainable ventures (see Program in Focus). This may be corrected if policy programs increase support to the ecosystem for producing a higher number of quality start-ups (see overall policy recommendations). This type of start-up is key for sustainability, as the research from Endeavor Insight in New York shows (Morris 2015). If the ecosystem cannot produce enough success stories whose founders reinvest in the ecosystem through mentorship (for example, through simple mentorship or angel investment) the ecosystem will not be sustainable over time.

Second, Circular 331 may be crowding out private sector led investment. To phase out Circular 331 in an orderly manner, private sources of investment should be introduced and crowed in. BDL should prepare for sustainability of the early stage funding and reducing the crowd out effect in private sector led investment.

\section{Constraints}

Address processes constraints. The transaction constraints highlighted by entrepreneurs puts Beirut on a par with very early stage ecosystems, such as Tanzania, making start-up creation burdensome for founders and diverting attention and resources at an early stage. In a similar advancing ecosystem, such as in West Bank \& Gaza, renting office space and hiring employees can be done in half the time, credit loan processes are six times faster, and funding processes three times faster. Policy reforms can streamline these processes by establishing specific conditions for start-ups processes (for example, reducing requirements).

\section{BOX 3.2 WHAT ARE CODING BOOTCAMPS?}

Coding bootcamps are intensive short-term programs, typically lasting three to six months, designed to train participants in programming skills to make them immediately employable in entry-level tech positions. ${ }^{27}$ In essence, they combine characteristics of traditional vocational training programs with the intensity of military bootcamps for new recruits, intermingling soft and tech skills learning in an intense manner, in what could be referred to as "skills accelerators." Coding bootcamps follow a structured process with three main characteristic features: 1 ) intense rapid skills training; 2) an experiential learning approach; and 3) curricula based on, and continuously adapting to, industry's demand.

Although the bootcamps methodology has primarily focused on coding skills, it has been also adapted for business and entrepreneurial skills as well as other technical skills. Usually, bootcamp programs embed "life skills" in their curriculum, enabling their graduates to be competitive irrespective of the industry in which they choose to work, for example, the ability to master new knowledge quickly and efficiently, effectively work in a team, meet tight deadlines, and so on. Evidently, these "life skills" belong to the subset of future-proof soft skills (World Bank.2017). 


\section{Program in Focus: Circular 331}

In August 2013, BDL announced Circular 331, injecting the potential of $\$ 400$ million into the Lebanese enterprise market. ${ }^{32}$ Circular 331 guarantees 75 percent of the banks' investments in the knowledge economy through direct start-up equity investment or indirect start-up support entities.

Local banks receive a seven-year interest-free credit from BDL, which can be invested in treasury bonds with an interest rate of 7 percent. In return, the bank commits to investing in the knowledge economy. Local banks can invest up to 3 percent of their capital in start-up support entities, funds, or directly into start-ups. BDL guarantees 75 percent of the investment, derisking it by mitigating the potential losses and reducing them to a mere 25 percent. Circular 331 is designed to diminish risk for the conservative local banks and does so by dictating the banks' portfolio diversification. A bank can invest up to 10 percent (of its 3 percent) in any one start-up, thus spreading the risk. BDL takes on 75 percent of the risk and only 50 percent of any profit made, making it attractive for local banks.

Responses to our survey suggest that Circular 331 has increased access to funding, but not necessarily smart funding, and that the funding has not increased education and training opportunities. The majority of respondents, however, agreed that overall, the program has been helpful in catalyzing the investment and support ecosystems (see Figures B.1 and B.2).

\section{FIGURE 2.16 CIRCULAR 331 EFFECTIVENESS IN VARIOUS AREAS}

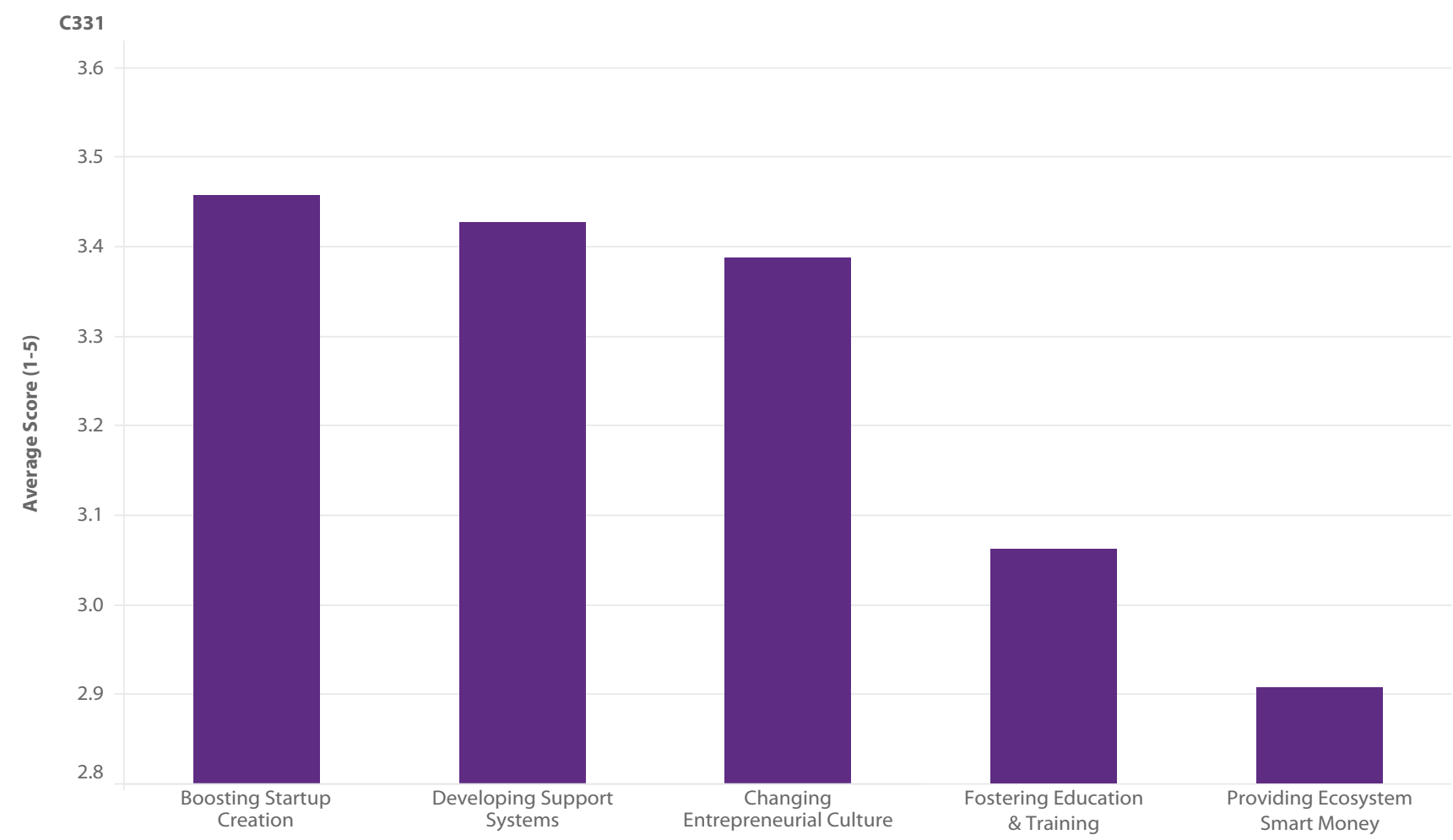


Entrepreneurs surveyed seemed to suggest that the program may benefit financial institutions more than start-ups themselves, and there is a risk in providing too much funding without a quality pipeline of start-ups.

These results should be interpreted somewhat cautiously given that many survey outreach partners benefitted from Circular 331, and as such they may have been biased in reaching out to respondents who were more likely to have benefitted from the program.

"Regarding Circular 331, I believe it is a positive contribution to fostering the growth of the tech sector in Lebanon. On the other hand, the risk is to fund start-ups without valid business prospects, especially if the incentives of the different parties are not aligned properly."

"Can't find tech employees anymore, they are all entrepreneurs funded by $331 . "$

"Circular 331 should be extended beyond banks to any investor or any start-up founder that is willing to move its operations to Lebanon. Banks do not need or deserve guarantees as they bring no additional value to the table and have more money than they know what to do with."

\section{FIGURE2.17 EFFECT OF CIRCULAR 331 ON RAISING FUNDING AND DEVELOPING THE SUPPORT SYSTEM}

Easier to Raise Funding?

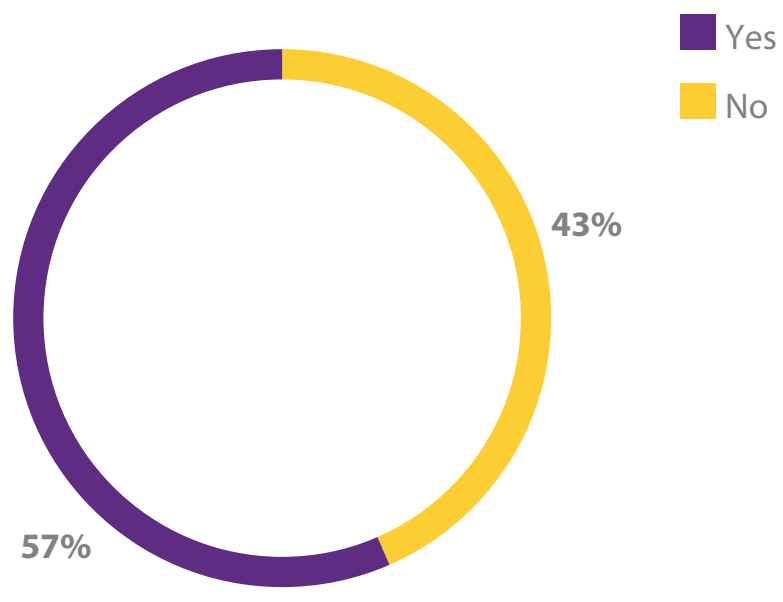

Easier to Develop Support System?

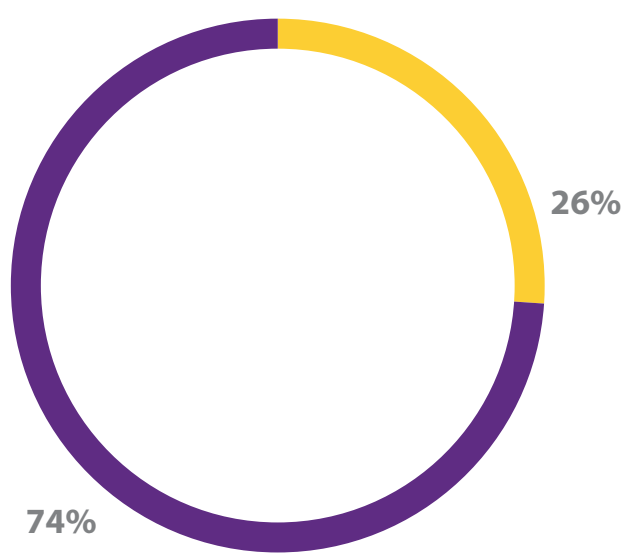




\section{References}

Baird, Ross, Lily Bowles, and Saurabh Lall. 2013. Bridging the "Pioneer Gap": The Role of Accelerators in Launching High-Impact Enterprises. Aspen Network of Development Entrepreneurs and Village Capital. https://assets.aspeninstitute.org/ content/uploads/files/content/docs/ande/Bridging $\% 20$ the\%20Pioneer\%20Gap\%20The\%20Role\%20of\%20 Accelerators\%20in\%20Launching\%20High\%20Impact\%20 Enterprises\%20.pdf.

BMG Research and Leandro Galli. 2013. Demand for Mentoring Among SMEs. BIS Research Paper Number 158. London: Department for Business Skills and Innovation. https://www.gov.uk/government/uploads/system/uploads/ attachment_data/file/263226/demand_for_mentoring among_SMEs.pdf.

Comin, Diego, and Bart Hobijn. 2010. “An Exploration of Technology Diffusion." American Economic Review 100 (December): 2031-2059. https://www.aeaweb.org/ articles?id=10.1257/aer.100.5.2031.

Comin, Diego, and Mestieri Marti. 2013. "Technology Diffusion: Measurement, Causes and Consequences." In Handbook of Economic Growth, Volume 2, edited by Philippe Aghion and Steven Durlauf, 565-622. Amsterdam: North Holland.

Getz, Daphne, and Itzhak Goldberg. 2016. Best Practices and Lessons Learned in ICT Sector Innovation: A Case Study of Israel. Background Paper for the Word Development Report 2016. Washington, DC: World Bank. http://pubdocs. worldbank.org/en/868791452529898941/WDR16-BP-ICTSector-Innovation-Israel-Getz.pdf.

I-DEV International. 2014. Measuring Value Created by Impact Incubators and Accelerators. I-DEV International, in conjunction with the Aspen Network of Development Entrepreneurs (ANDE) and Agora Partnerships. https://assets.aspeninstitute. org/content/uploads/files/content/docs/resources/ ANDE\%20I-DEV\%20INCUBATOR\%20REPORT\%2011-2114\%20FINAL\%2OFOR\%20DISTRIBUTION.pdf.
Isaksson, Anders, Thiam Hee Ng, and Ghislain Robyn. 2005. Productivity in Developing Countries: Trends and Policies. Vienna: United Nations Industrial Development Organization. http://www.unido.org/fileadmin/ user_media/Publications/Pub_free/Productivity_in_ developing_countries_trends_and_policies.pdf.

ITIF (Information Technology and Innovation Foundation).2017. Learning from Leading Startup Ecosystems. Washington, DC: ITIF. https://itif.org/ events/2017/05/02/learning-worlds-leading-startupecosystems.

Morris, Rhett. 2015. “Mentors are the Secret Weapons of Successful Startups."TechCrunch Network, March 22. https://techcrunch.com/2015/03/22/mentors-are-thesecret-weapons-of-successful-startups/.

Mulas, Victor, and Mikel Gastelu-Iturri. 2016. New York City: Transforming a City into a Tech Innovation Leader. Washington, DC: World Bank. https://openknowledge. worldbank.org/handle/10986/25753.

Mulas, Victor, Michael, Minges, and Hallie Rocklin Applebaum. 2015. Boosting Tech Innovation Ecosystems in Cities: A Framework for Growth and Sustainability of Urban Tech Innovation Ecosystems. Washington, DC: World Bank Group. https://openknowledge.worldbank.org/ handle/10986/23029.

OECD (Organization for Economic Co-operation and Development). 2007. Eurostat-OECD Manual on Business Demography Statistics. Paris: OECD. http://www.oecd.org/ std/39974460.pdf.

World Bank. 2017. Coding Bootcamps: Building FutureProof Skills through Rapid Skills Training. Washington, DC: World Bank. http://documents.worldbank.org/ curated/en/795011502799283894/Coding-bootcampsbuildingfuture-proof-skills-through-rapid-skills-training. 


\section{Appendix A Survey Methodology and Analysis}

\section{Methodology}

\section{Survey Questions}

The survey of start-up founders used the standard questionnaire developed under the Global Entrepreneurship Research Network (GERN) with some additional questions to understand specific constraints faced by start-ups. The GERN-developed standard questionnaire includes the following sections:

1. Educational history (including vocational, bootcamps, and certificate programs)

2. Employment history

3. Founding history (serial entrepreneurship)

4. Support programs (for example, acceleration, incubation, and so on) history

5. Connections with mentors and mentees

6. Connections with investors (angel and institutional)

In addition to this information, the survey captured the geographic location of start-ups and intermediaries (for the geographic analysis) and included the following standard questions:

7. Incorporation: On average, how many days did it, or would it, take you to incorporate a new start-up?

8. Funding: On average, how many days did it, or would it, take you to set up a bank account for your start-up?

9. Credit: On average, how many days did it, or would it, take you to get a line of credit for your start-up?

10. Funding: On average, how many days did it, or would it, take you to raise a round of equity funding?

11. Hiring: On average, how many days did it, or would it, take you to hire an employee, from job posting to employee start?

12. Office space: On average, how many days did, it or would it, take you to obtain office space for your start-up?

13. Exit: On average, how many days did it, or would it, take you to exit your start-up?
Additional questions were included regarding Circular 331:

1. On a scale of 1 to 5 , how effective do you think Circular 331 was in developing support systems (incubators, accelerators, and so on)?

2. On a scale of 1 to 5 , how effective do you think Circular 331 was in providing smart money to the ecosystem?

3. On a scale of 1 to 5, how effective do you think Circular 331 was in boosting start-up creation?

4. On a scale of 1 to 5, how effective do you think Circular 331 was in fostering education and training?

5. On a scale of 1 to 5, how effective do you think Circular 331 was in changing the entrepreneurial culture?

6. Did Circular 331 make it easier for you to raise funding?

7. Did Circular 331 make it easier for you to develop a support system (that is, attend an incubator or accelerator)?

\section{Outreach Strategy}

Entrepreneurs filled in an online survey available at http://survey.techecosystems.org/, which was disseminated through partnership with local organizations by email and word of mouth. These partners played a crucial role in not only identifying start-ups, but also connecting and introducing the study team and the survey to start-ups.

Partners included Endeavor Lebanon, ArabNet, Berytech, USEK community, SETT (Startup Ecosystem Think Tank), UK Lebanon Tech Hub, Wamda, AltCity, Bader, Lebanon for Entrepreneurs (LFE), Lebanon Knowledge Network, MIT Enterprise Forum of Pan Arab Region, Balamand University, BIAT Business Incubation Association, TEC (Tripoli Entrepreneurs Club), Lebanon Internet Society, Ministry of Economy and Trade, Smart ESA, South Accelerator, Startup Megaphone, and the American University of Beirut (AUB). 


\section{Data Pipeline}

Survey data used in this report originated with this custom survey and was initially retrieved in raw JSON (JavaScript Object Notation) format. Data was converted to CSV (commas separated values), combined with raw data from additional sources, then cleaned of outliers and testing data. Nodes without location data, and locations without geocodes, were passed through the Google Maps application programming interface (API) in order to obtain standardized location data wherever possible. This new dataset was deduplicated using a process that marked similarities between names, email addresses, URLs, and dates. Entities that were determined to be likely duplicates were then merged, maintaining all existing data and privileging more recent data in the event of conflict. Duplicate edges resulting from this process were removed. Finally, college majors and company industries were categorized using a machine learning approach that used a set of manually categorized responses to predict category based on word similarity. From this cleaned and augmented dataset, a panel and graph data dataset for analysis were then generated.

\section{Limitations}

It is difficult to determine whether the sample is representative. The collection of the data was heavily dependent upon the participation of individuals in existing networks, and as such the networks of the study's partners are likely to be overrepresented. There is also a possibility that sub-segments of the of the ecosystem have been dropped or were never part of the outreach networks, and as such they would not end up in the resulting data sample. To a certain extent, this bias is not problematic, as it means that the data and analysis document those individuals and nodes that are actively and currently engaged in developing the ecosystem. This suggests that they are also more likely to participate in and respond to policies designed to develop the ecosystem. However, since there are few other databases with which to compare the data, it is difficult to assess exactly whether the sample is truly representative.

The sample is small and influenced by outliers. To address this, where possible medians rather than means were used as descriptive statistics. Some of the analysis (for example, that of "successful" start-ups) relies on very small portions of the dataset, and thus give relatively weak information on unobserved, population-level characteristics.

Data cleanliness is difficult to evaluate. Missing data could represent a true lack of connection in the ecosystem, or potentially could be the result of respondents dropping off the survey due to technical issues or a lack of interest to complete the survey. Sometimes conflicting dates or meta information was recorded from multiple sources, in which case the source closest to the entity (that is, the founder) was privileged. In addition, respondents were expected to accurately select names of entities already in the database through an autofill mechanism in order to properly attribute new information to existing entries. Although a machine learning driven data deduplication process was employed before analysis, this may not have resolved every duplicated entry, and such fuzziness may affect exact numbers in the social network analysis.

The sample is highly influenced by survivorship bias. Entrepreneurs that are so successful that they leave the ecosystem were not captured. For example, the lack of strong evidence for serial entrepreneurs in Beirut may suggest that, once they have had one successful venture,

\section{TABLE A.1 START-UPS BY FOUNDING YEAR}

2016

22

2015

25

2014

8

2013

14

2012

20

2011

13

2010

9

2009

8 
they pursue subsequent start-ups in other more developed ecosystems, rather than that they do not repeatedly start businesses. Currently there is no simple way to capture data on those individuals that leave, or a way of identifying them in the dataset. In addition, the survey only captures entrepreneurs who were active during the survey period, and as such it does not capture failed entrepreneurs who have dropped out of the ecosystem.

In order to reduce the survey length in an attempt to boost response rates, the survey was necessarily limited in scope. This means that there are some analyses that were not explored, such as limitations in recruiting skilled employees (including engineers) or in internet connectivity.

The analysis includes data across start-ups and SMEs across a range of ages and neighborhoods. Due to limitations on sample size and accurate geographic data, it was not possible to conduct the analysis on each age or neighborhood cohort separately. As such, the analysis may miss more nuanced findings related to time or geography.

\section{Analysis}

Stakeholders in the Lebanese start-up ecosystem can be represented using a social network comprised of nodes (people, organizations, groups, and events), and edges, which are the relationships between them. For the social network analysis, an edge was considered as a part of the ecosystem if either of its endpoints are in the region. From these edges, relevant nodes for the network were extracted. Technically, the network is multipartite. However, given that individual investors can function similarly to institutional investors, founders of small start-ups are practically synonymous with their companies, and events and groups are often start-ups themselves, the network is treated as if it only contains one type of entity in order to simplify exploration.

Nodes are never removed from the dataset, even if the represented entity no longer exists. In other words, once a start-up has appeared in the dataset, it remains there for all subsequent years (see Figure A.1). There were two reasons for this decision. First, accurate enddates for start-ups were difficult to gather. Second, the primary interest was in mapping the social dimensions of the start-up network, not creating a year-by-year catalogue of start-ups. Although start-ups may close, socially they still function as nodes within the urban innovation ecosystem that may introduce other nodes to second-order connections.
FIGURE A.1 CUMULATIVE SUMMARY OF NODES

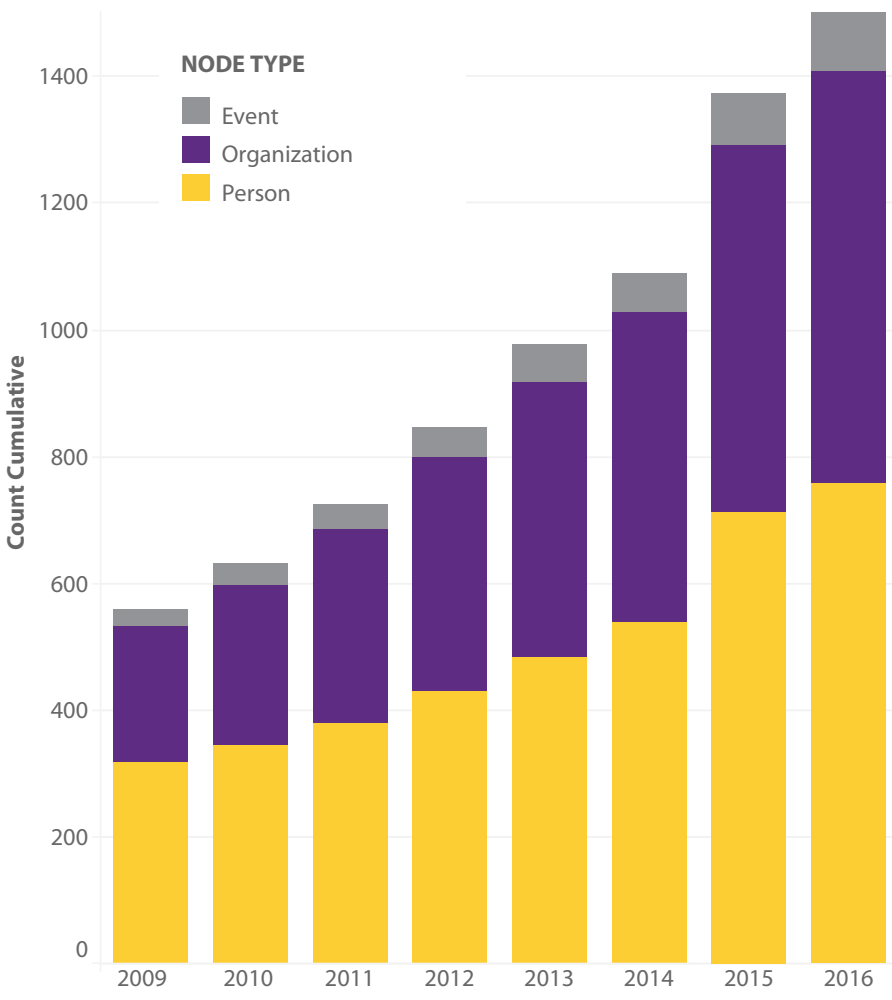

FIGURE A.2 CUMULATIVE SUMMARY OF EDGES

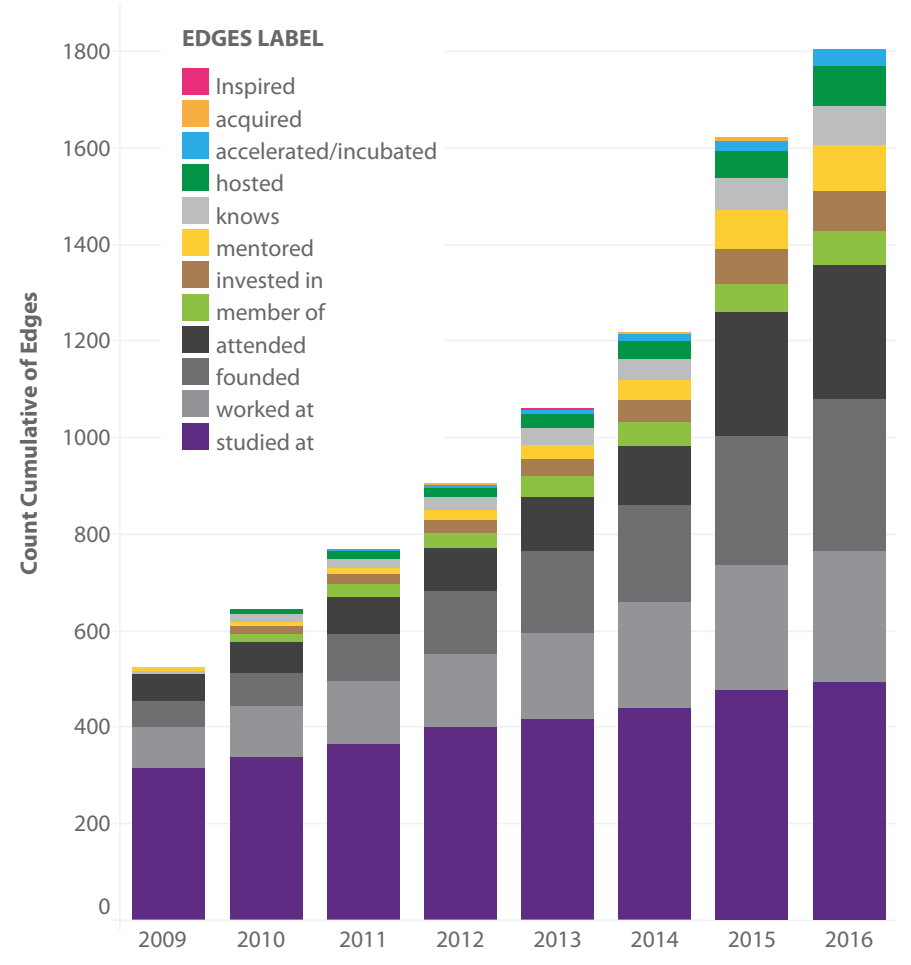




\section{BOX A.1 WHAT IS CENTRALITY?}

By calculating centrality measures of stakeholders in the dataset, key players in the community can be identified quantitatively.

The diagrams below, while not specific to our dataset, help illustrate the definition and interpretation of each type of centrality. Red indicates higher centrality values. Blue indicates lower centrality values.

Degree centrality measures the number of other nodes within the ecosystem each node is directly connected to. It does not take into account any second-order connections.

Closeness centrality measures a node's social distance to other nodes. It is expressed as the inverse of the average distance from each node to every other node in the network. A low closeness centrality indicates that the firm is on the edge of the network.

Eigenvector centrality augments degree centrality by taking into account the connectivity of the nodes a node is connected to. Highly connected nodes within highly interconnected clusters have high eigenvector centrality.

Betweenness centrality measures how many times a node acts as a gateway in the network. The higher the betweenness centrality of a firm, the more paths run through that firm to connect two other firms. High betweenness centrality means that a node is a key bridge or facilitator between different clusters.

Source: Diagrams are from https://en.wikipedia.org/wiki/Centrality.

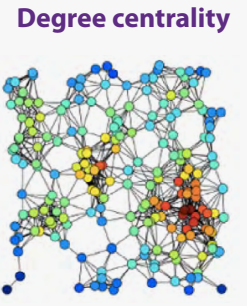

Closeness centrality

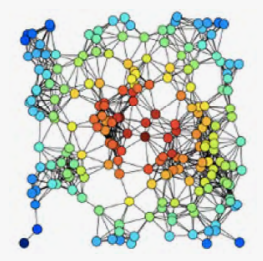

Eigenvector centrality

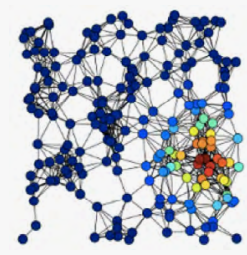

Betweenness centrality

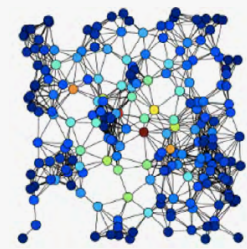

Calculating centrality measures on different subnetworks in the data builds understanding of which players in the ecosystem are the most important. In the case of Beirut, the analysis reveals that accelerators and incubators are the most connected of all key players, and they are the connectors in the ecosystem (see Table A.2). However, the ecosystem appears be one big cluster without much complexity, and key players are more or less evenly spaced in this cluster.

\section{TABLE A.2 CENTRALITY OF KEY PLAYERS IN NETWORK}

\begin{tabular}{|c|c|c|c|c|}
\hline & Degree & Betweenness & Eigenvector & Closeness \\
\hline Accelerator & 5.15385 & 35.2692 & $2.96326 \mathrm{E}-05$ & 5.99645E-07 \\
\hline Founder & 4.5 & 4.29082 & $3.99248 \mathrm{E}-05$ & 5.99934E-07 \\
\hline Investor & 4.575 & 10.0875 & 3.30187E-05 & $6.00092 \mathrm{E}-07$ \\
\hline School & 2.93966 & 2.51293 & 2.47913E-05 & $5.97778 \mathrm{E}-07$ \\
\hline Start-up & 2.90071 & 1.23404 & 1.34049E-05 & 5.97793E-07 \\
\hline
\end{tabular}

Note: While in other regions we have calculated centralities for sub-projections of the overall network, the low density of the reported network in Beirut limited the usefulness of reporting these numbers. As such, we have excluded these tables from this report. 


\section{Short-Term Success}

A fixed effects logit model was used where the dependent variable is the probability of the start-up raising funding in a given year of existence ${ }^{33}$ and the explanatory variables are lagged in order to gauge the effect of centrality in the investment network on a start-up's short-term success. Only the degree of centrality is a direct measure of the number of investors a start-up has. Eigenvector and closeness centrality capture the effects of second-order and beyond connections to investors.

The logit regression allows us to capture the binary outcome of raising versus not raising funding while maintaining interpretability. To understand the effect of each explanatory variable on the probability of raising funding, we calculate the odds ratio by taking $\mathrm{e}^{\wedge}$ (estimated coefficient). The odds ratio is a multiplier. If the odds ratio is 1.5 , for example, then a unit increase in the dependent variable increases the likelihood of raising funding by $50 \%$.

The greater a start-up's closeness centrality, the more likely it is to raise funding in the next year. In addition, older start-ups are more likely to raise funding. However, these effects are offset by the finding that the more direct investment connections the start-up has, the less likely it is to get funding in the next year, and start-ups with greater eigenvector centrality that are well connected within a cluster of accelerators, investors, and funded start-ups are less likely to raise funding. The negative effects are likely due to the fact that once a start-up has received funding once, it is less likely to need it in future periods and that the main cluster of accelerators, investors, and funded start-ups is immature.
These results suggest that there appears to be a main cluster in the investment ecosystem that has only recently developed, and the majority of activity is occurring in this immature cluster. This hypothesis is supported by a comment from a survey respondent who stated, "I wish it wasn't centralized in limited number of VCs and banks that are all in one bundle and interconnected. some competition between the VCs and the programs would push them to provide better services."

\section{Long-Term Success}

In the long-term, we are interested in a start-up's ability to create jobs for the ecosystem. As such, we use a logit model where the dependent variable is hiring occurrence weighted by years of existence, such that we capturing the percentage of years that the firm hires employees. ${ }^{35}$ For simplicity, we can also interpret this number as the average probability a firm will hire in a given year.

Well-funded start-ups are more likely to consistently hire. An additional founder increases hiring likelihood by 17 percent, and additional work experience increases hiring likelihood by 24 percent. Participation in acceleration programs and mentorship relationships have no significant effect on long-term hiring probabilities. Serial entrepreneurs are less likely to hire consistently, suggesting an opportunity to increase the overall quality of the start-up ecosystem as a learning mechanism for founders. There is no significant impact of educational factors on job creation.

\section{TABLE A.3 EFFECT OF CENTRALITY IN INVESTMENT NETWORK ON SHORT-TERM FUNDING SUCCESS ${ }^{34}$}

\begin{tabular}{|c|c|c|c|c|c|}
\hline & Estimate & Std. Error & z value & $\operatorname{Pr}(>|z|$ & \\
\hline startup_prev_degree_all_investment & $-1.279 e+09$ & $2.201 e+07$ & $-5.810 e+01$ & $<2 e-16$ & $\star \star \star$ \\
\hline startup_prev_eigenvector_all_investment & $-2.667 e+26$ & 2. & $-1.085 e+18$ & $<2 e-16$ & $\star \star \star$ \\
\hline startup_prev_closeness_all_investment & $1.329 e+14$ & $e+11$ & 1. $358 e+02$ & $e-16$ & $\star \star \star$ \\
\hline year existence & $1.103 e+07$ & $3.158 e+06$ & $3.494 e+00$ & 0.00055 & $\star \star \star$ \\
\hline
\end{tabular}

\section{TABLE A.4 EFFECT OF START-UP CHARACTERISTICS ON LONG-TERM FUNDING SUCCESS}

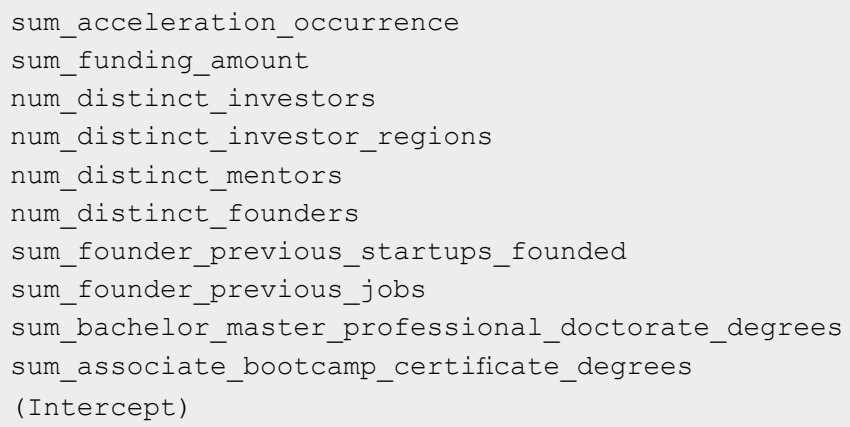

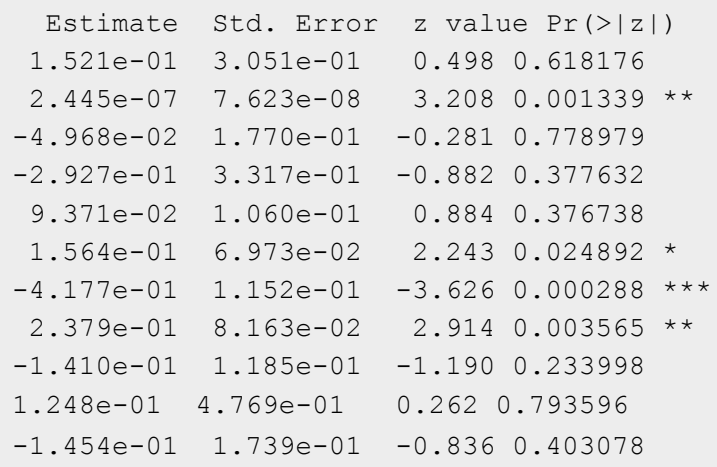


1. As a reference for the sample size, the Investment Development Authority in Lebanon (IDAL) reported 800 companies in the IT sector, with 200 companies focused on software development, in Lebanon in 2005. See: IDAL ICT Sector Statistics in Lebanon (2015). http://www.investinlebanon.gov.lb/Content/uploads/ SideBlock/160307124909480 ICT\%20Statistics\%202015.pdf

2. https://startupgenome.com/.

3. http://www.digital.nyc/.

4. http://www.techmap.london/.

5. https://www.galidata.org/.

6. See "Outreach Partners" in Appendix A for full list of partners.

7. See "Limitations" section in Appendix A for more information on the limitations to our approach.

8. The methodology of this analysis is focused on the founder's perspective and how that compares across regions. Founders in a given city may not perceive an existing constraint as such because they have adapted to the environment and do their business despite of such constraints.

9. https://techcrunch.com/2015/03/22/mentors-are-the-secretweapons-of-successful-startups/.

10. The data collected for this analysis suffers from an inherent survivorship bias, the precise impact of which is difficult to quantify (see "Limitations" section in Appendix A for more details).

11. We did not collect data on costs associated with these procedural tasks as the numbers were less directly comparable across regions.

12. Of 255 instances of founding, only 43 percent (110) of those instances have the age of the founders available.

13. Gross enrollment in tertiary education in Lebanon for both sexes was 38 percent in 2015 (http://data.uis.unesco.org/).

14. For example, postgraduate qualification in law, business, or medicine.

15. Of 255 instances of founding, only 48 percent (124) of those instances have major available.

16. Of 636 instances of work history at the time of founding, 52 percent (336) have job level listed.

17. Since start-ups can relocate, this list includes some accelerators that are not themselves in Lebanon.

18. Ratio of accelerated firms that received investment over nonaccelerated firms that received investment. A ratio of 1 means equal opportunities. A ratio below one means nonaccelerated firms are more likely to receive investment. A ratio of more than one means accelerated firms are more likely to receive investment.
19. 55 distinct start-ups received funding out of a total of 142 unique start-ups.

20. Ratio of the number of investments received by funded start-ups that were accelerated divided by the number of investments received by funded start-ups that were not accelerated.

21. https://techcrunch.com/2015/03/22/mentors-are-the-secretweapons-of-successful-startups/.

22. Events reported included: Lebanon Open Innovation Week, Africa Open Data Conference, Megawatt Challenge, and Women for Resilience Cities.

23. This is confirmed by respondents to the survey. One participant stated that, "Players in the ecosystem, for example, incubators, hubs, accelerators, and so on, should work together to build a stronger ecosystem rather than competing and dividing opportunities."

24. As one responder to the survey stated: "Regarding Circular 331, I believe it is a positive contribution to fostering the growth of the tech sector in Lebanon. On the other hand, the risk is to fund startups without valid business prospects, especially if the incentives of the different parties are not aligned properly." See Program in Focus.

25. http://www.datacity.paris/.

26. There are very few active bootcamp provider operating in Lebanon, the most active one being SE Factory.

27. http://www.skilledup.com/articles/the-ultimate-guide-to-codingbootcamps-the-exhaustive-list.

28. https://tampere.demola.net/.

29. https://tech.cornell.edu/jacobs-technion-cornell-institute/overview.

30. http://www.startupchile.org/.

31. http://www.k-startupgc.org/.

32. http://2015.bdlaccelerate.com/everything-you-need-to-knowabout-bdl-circular-331/; and http://fletcher.tufts.edu/ /media/ Fletcher/Microsites/IBGC/Student\%20Research/IBGC_Circular_331. pdf.

33. The amount of funding raised is not accounted for, since this is heavily influenced by the type of business and prone to outliers.

34. For this regression, start-ups were restricted to those founded after 2008 in order to avoid confounding influences from the global financial crisis.

35. The number of employees hired is not accounted for, since this is heavily influenced by the type of business and prone to outliers. 

This work is available under the Creative Commons Attribution NonCommercial 3.0 IGO license (CC BY NC 3.0 IGO). Under the Creative Commons Attribution Non-Commercial license, you are free to copy, distribute, transmit, and adapt this work for non-commercial purposes, under the following conditions: Attribution-Please cite the work as follows: Mulas, Victor; Qian, Kanty; and Henry, Scott. 2017. Tech Start-up Ecosystem in Beirut. Findings and Recommendations. License-Creative Commons Attribution Non-Commercial CC 3.0 IGO Translations-If you create a translation of this work, please add the following disclaimer along with the attribution: This translation was not created by The World Bank and should not be considered an official World Bank translation. The World Bank shall not be liable for any content or error in this translation. Adaptations-If you create an adaptation of this work, please add the following disclaimer along with the attribution: This is an adaptation of an original work by The World Bank. Responsibility for the views and opinions expressed in the adaptation rests solely with the author or authors of the adaptation and are not endorsed by The World Bank. Third-party content-The World Bank does not necessarily own each component of the content contained within the work. The World Bank therefore does not warrant that the use of any third-party-owned individual component or part contained in the work will not infringe on the rights of those third parties. The risk of claims resulting from such infringement rests solely with you. If you wish to re-use a component of the work, it is your responsibility to determine whether permission is needed for that re-use and to obtain permission from the copyright owner. Examples of components can include, but are not limited to, tables, figures, or images. All queries on rights and licenses should be addressed to the Publishing and Knowledge Division, The World Bank, 1818 H Street NW, Washington, DC 20433, USA; fax: 202-522-2625; e-mail: pubrights@ worldbank.org

\section{(1)(9)}

